\title{
Non-adiabatic pressure loss boundary condition for modelling turbocharger turbine pulsating flow
}

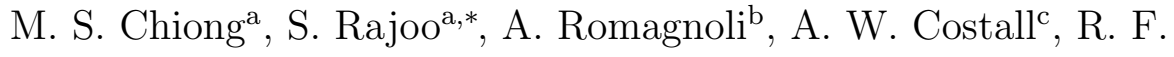 \\ Martinez-Botas ${ }^{\mathrm{c}}$ \\ ${ }^{a}$ UTM Centre for Low Carbon Transport in cooperation with Imperial College London, \\ Universiti Teknologi Malaysia, 81310 Johor, Malaysia \\ ${ }^{b}$ School of Mechanical and Aerospace Engineering, Nanyang Technological University, \\ N3.2-02-32, 50 Nanyang Avenue, Singapore 639798, Singapore \\ ${ }^{c}$ Dept. of Mechanical Engineering, Imperial College London, London SW7 2BX, UK
}

\section{Abstract}

This paper presents a simplified methodology of pulse flow turbine modelling, as an alternative over the meanline integrated methodology outlined in previous work, in order to make its application to engine cycle simulation codes much more straight forward. This is enabled through the development of a bespoke non-adiabatic pressure loss boundary to represent the turbine rotor. In this paper, turbocharger turbine pulse flow performance predictions are presented along with a comparison of computation duration against the previously established integrated meanline method. Plots of prediction deviation indicate that the mass flow rate and actual power predictions from both methods are highly comparable and are reasonably close to experimental data. However, the new boundary condition required significantly lower computational time and rotor geometrical inputs. In addition, the pressure

\footnotetext{
*corresponding author

Email address: srithar@fkm.utm.my (S. Rajoo)

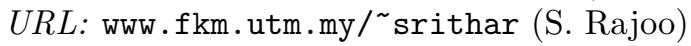


wave propagation in this simplified unsteady turbine model at different pulse frequencies has also been found to be in agreement with data from the literature, thereby supporting the confidence in its ability to simulate the wave action encountered in turbine pulse flow operation.

Keywords: Turbocharger, Turbine, One-dimensional, Non-adiabatic pressure loss, Unsteady flow, Modelling

\section{Introduction}

2 Turbocharging is regarded as one of the key elements in the success of downsized internal combustion engine systems, an effective strategy towards $4 \mathrm{CO}_{2}$ emissions reduction. These days, a turbocharger is no longer restricted

formance, in terms of minimizing fuel consumption while maintaining good transient response. In current industry practice, engine modelling does not consider the full unsteady analysis of the turbocharger turbine, but instead treats it as a quasi-steady device. While this traditional approach can provide adequate simulations of the engines steady state engine performance, its deficiencies become apparent when attempting to accurately predict transient response [5], especially so when the desire is to predict the benefit of turbocharger technologies such as twin scroll turbines. Numerous unsteady turbine models have been developed over the years, yet none of these models 
have been widely implemented into commercial one-dimensional engine cycle simulation codes, mainly due to the associated complexity.

\subsection{Background study}

Commercial one-dimensional engine cycle simulation software tools model the turbocharger turbine by following a quasi-steady approach (turbine inlet and outlet are considered as the points where the flow conditions are experimentally measured). However, due to the reciprocating nature of the engine, the flow entering the turbine is of a pulsating nature, the form of which varies depending on engine speed, displacement, number of cylinders, etc. Over the last fifty years, several researchers have investigated this phenomenon, showing that during each engine cycle the instantaneous mass flow measured at the turbine inlet does not follow the steady-state characteristic, but instead forms an unsteady hysteresis loop, particularly at lower pulse flow frequencies [6-17]. The unsteady characteristic was also found (experimentally [16] and analytically [18]) to vary in accordance with turbine inlet pulse frequency. However, detailed experimental flow field investigations of the turbine [19] suggest that the rotor itself does operate in quasi-steady manner (compared to the turbine stage as a whole), and this has been analytically supported by Strouhal number analyses [16, 20] and 3D CFD [21-23]. This leaves the turbine volute as the primary source of the observed unsteadiness.

The major deficiency of a quasi-steady turbine model is therefore the lack of a spatial dimension (or dimensions), and the consequent inability to account for the flow dynamics taking place within the turbine volute during pulsating flow operation. Ref. [23] further highlighted the deficiencies of a quasi-steady turbine model where the temperature dependent heat transfer 
and mechanical losses do not vary according to on-engine conditions but are restricted to the measured "apparent" steady-state characteristic [24]. Thus modelling improvements have been obtained by incorporating, as a first step, the volume of the volute in a 0D or "filling-and-emptying" approach [25], and taking it a step further by explicitly modelling the volute as a one-dimensional form to additionally capture pressure wave action effects [23, 26-33].

In order to model the quasi-steady and unsteady characteristics of the turbine rotor and volute respectively, an adiabatic pressure loss (APL) boundary and a series of 1D tapered (non-constant cross-sectional area) pipe ducts have previously been considered [30, 34]. Once calibrated for steady flow conditions, this type of unsteady turbine model has shown its ability to capture the wave action phenomena under pulsating flow operation, reflected in the swallowing capacity hysteresis prediction and the correct variation trend against growing pulsating flow frequency [18]. Although this model showed satisfactory unsteady mass flow prediction, prediction of instantaneous turbine power was less convincing. In an attempt to improve power prediction [35], a turbine meanline model was integrated into the 1D model. From the established flow state, the meanline model makes a performance prediction using a number of empirical loss relations, which are in turn based on knowledge of the turbine geometry and operating parameters. Validation at different pulse flow frequencies suggested good potential for the integrated 1D-meanline turbine model [36, 37], but this new methodology, although innovative, has a few potential downsides.

Firstly, the meanline model required detailed rotor geometrical inputs, e.g., rotor blade angle and tip-to-shroud clearance (this will be discussed fur- 
ther in Section 4). However, rotor geometrical information is rarely accessible especially during engine-turbocharger matching. Secondly, the instantaneous turbine power calculation was performed from the already established pulsating turbine instantaneous flow field, sampled into a complete pulse cycle such that the phase synchronization of the instantaneous velocity components extracted at different locations in the turbine volute can be accomplished (e.g., the gas flow velocity taken at the volute tongue for instantaneous rotor upstream tangential velocity calculation via the free-swirl relation). Even though this approach showed good results in cold-flow testing data validation, such a model may fall short during transient engine modelling in the absence of continuous complete pulse cycles under constant frequency. Lastly, the pressure loss boundary used in this methodology to establish the pulsating turbine flow field was considered to be adiabatic ${ }^{1}$ [38]. This is not the case in real operating conditions, it makes the downstream flow enthalpy prediction inaccurate and it prevents the model from being used in those operating conditions in which the downstream gas flow is re-used (e.g., presence of turbo-compounding systems, second-stage turbocharging, etc.).

In this paper, the development of a non-adiabatic pressure loss (NAPL) boundary as a turbine rotor boundary will be presented. The formulation details will first be presented in Section 2, followed by turbine steady-state performance validation in Section 3. The pulse flow turbine performance predictions will be compared with the literature unsteady experimental data [39] and with the meanline integration prediction method [37] (its formula-

\footnotetext{
${ }^{1}$ The boundary was originally formulated to model adiabatic flow devices, e.g., valve, throttle, gauze, etc., but not a turbine rotor.
} 
tion will also be briefly discussed in Section 2.5) at four pulsatile frequencies of three operating speeds in Section 4. In addition to flow prediction performance, the computational time for this NAPL rotor boundary will also be discussed in Section 5.

\subsection{Experimental results}

The experimental data used in this paper for model validation was generated in the cold-flow turbine test facility available at Imperial College London. The test facility features a low-inertia, high-speed permanent magnet eddy-current dynamometer as the loading device [39] and a rotary disc pulse generator to generate the pulse flow at different frequencies [9]. The turbocharger turbine studied here is of a single-entry mixed-flow turbine type in which the rotor was designed by [15] and coupled to a commercial nozzleless turbine volute. The steady and pulsating flow turbine performance has been experimentally evaluated at six operating speeds from 27.0 to 53.7 $\operatorname{rps} / \sqrt{\mathrm{K}}[39]$. Four pulse frequencies have been considered, viz., 20, 40, 60 and $80 \mathrm{~Hz}$ which correspond to the typical operating range of a medium-size four-stroke diesel engine. For the model prediction validation, three operating speeds will be considered, i.e., 27.0, 43.0 and $53.7 \mathrm{rps} / \sqrt{\mathrm{K}}$ and all four flow frequencies at these selected speeds will be analysed.

Since the experiment was conducted at cold-flow conditions (i.e., without the presence of a combustor but with only a small amount of upstream heating to avoid condensation at the turbine exit), the effects of heat transfer and bearing loss can be suppressed. This effectively eliminated the additional complexity that may have presented, e.g., the non-uniform heat flux in heat transfer as a result of volute cross-section [40-42], and the variation of lubri- 
cant viscosity and bearing loss at elevated temperature [43, 44]. Therefore, the experimental data can be considered as purely the turbine aerodynamic performance.

\section{Mathematical Model}

\subsection{Computational domain}

The unsteady turbine model domain has undergone a series of advancement throughout the previous works on this subject, viz. from a single constant cross-sectional area pipe of equivalent volume representing the turbine volute, to sections of tapered pipes with equivalent area variation and volume changes, before multiplying the number of rotor entries to resemble more realistic flow entry into the rotor wheel [30, 34-37]. As a consequence of the new model domain which required more detailed volute geometrical information, the quality of the prediction improved significantly. For instance, the varying cross-sectional volute model area made the prediction of dimensional parameters possible whereas only non-dimensional parameters could be predicted in the initial stage model. The addition of multiple rotor entries around the volute azimuth angle also proved capable of capturing the actual phase of the pulsating flow energy transfer into the rotor. These features are essential to achieve a turbine model that could be easily integrated into engine software for real time engine simulation.

The computational domain used in this paper follows that used in Ref. [37], as illustrated in Fig. 1. The turbine volute (inlet to $360^{\circ}$ azimuth angle) is modelled as a series of pipes with varying areas, summarized in Table 1 [45]. The flow from the turbine inlet is assumed to merge into a single pipe from 
156

$$
\mathbf{W}=\left[\begin{array}{c}
\rho F \\
\rho u F \\
\rho e_{0} F
\end{array}\right], \mathbf{F}(\mathbf{W})=\left[\begin{array}{c}
\rho u F \\
\left(\rho u^{2}+p\right) F \\
\rho u h_{0} F
\end{array}\right], \mathbf{C}=\left[\begin{array}{c}
0 \\
-p \frac{d F}{d x} \\
0
\end{array}\right]+\left[\begin{array}{c}
0 \\
\rho G F \\
-\rho q F
\end{array}\right]
$$

\footnotetext{
${ }^{2}$ The free-swirl modelling would require at least two-dimensional modelling, i.e., mean flow path and additional radial dimensions.
} 
The numerical solution discretizes ${ }^{3}$ the governing equations across the model domain. From a pre-defined initial state, the domain instantaneous flow state is solved using the classical two-step Lax-Wendroff scheme combined with a TVD (total variation diminishing) flux limiter to ensure a shockcapturing, second-order accurate flow prediction. The Swamee and Jain friction model [46] and the Reynolds analogy heat transfer model [47] are used to evaluate the friction and heat transfer term $(G$ and $q)$ respectively in the source term vector $\mathbf{C}$.

The model boundaries (located at turbine inlet, exit, between each pipe segment in Fig. 1, and the rotor boundary to be discussed in the next section) serve as the closure for the numerical calculation at each pipe domain end. At each time step, and for a given combination of incident waves $\left(\lambda_{\mathrm{in}_{1}}\right.$ and $\lambda_{\mathrm{in}_{2}}$ in Fig. 2), these boundaries compute and provide information on their influence on the domain flow state, i.e., the transmitted and reflected waves ( $\lambda_{\text {out }_{1}}$ and $\lambda_{\text {out }_{2}}$ respectively in Fig. 2).

[Figure 2 about here.]

Open-end boundaries have been used at the model inlet and exit. The experimental instantaneous stagnation pressure and temperature are defined at the inlet boundary condition which has been set to be anechoic to emulate the long pipe upstream to the measurement plane in the actual test facility. Ambient conditions have been defined at the model open-ended exit boundary condition, which has been extended by a dimension equal to the exducer

\footnotetext{
${ }^{3}$ The most promising ratio of discretization length over domain diameter has been recommended to be 0.55 [37] and is used here.
} 
diameter to allow for turbine downstream pressure fluctuations [37, 47]. Domain pipes are connected using an area variation boundary whereas the rotor entries (at $90^{\circ}, 180^{\circ}, 270^{\circ}$ and $360^{\circ}$ azimuth) are modelled using junction boundaries $[38,47]$. The selection of these boundaries has been validated in [37] with satisfactory instantaneous flow prediction. The simulation is executed in transient mode, and is considered to achieve convergence once sufficiently small changes ${ }^{4}$ in turbine and rotor inlet mass flow rate (less than $0.01 \%$ ) are observed.

\subsection{Non adiabatic pressure loss boundary}

The formulation of the NAPL boundary is in reference to the adiabatic pressure loss (APL) boundary presented by Benson [38] except for the governing equations. The position diagram of an NAPL device is shown in Fig. 2, and the gas flow velocity notation is taken as positive for gas flow towards the boundary. Parameters upstream of the device are denoted with subscript 1 and downstream as 2 .

For an APL device, the conservation of energy and continuity equations across the boundary are expressed as [38]:

Continuity equation:

$$
\rho_{1} u_{1} F_{1}=\rho_{2} u_{2} F_{2}
$$

\footnotetext{
${ }^{4}$ For steady-flow simulation, these changes are monitored over time, whereas in pulseflow simulation, these are monitored at the same pulse cycle angle over successive pulses.
} 
Energy equation:

$$
\begin{aligned}
& h_{0}=h_{1}+\frac{u_{1}^{2}}{2}=h_{2}+\frac{u_{2}^{2}}{2} \quad \text { or } \\
& a_{0}^{2}=a_{1}^{2}+\frac{\kappa-1}{2} u_{1}^{2}=a_{2}^{2}+\frac{\kappa-1}{2} u_{2}^{2}
\end{aligned}
$$

In order to realistically represent a rotor, the conservation of energy across the boundary must be associated with an additional stagnation enthalpy transfer term (given as $\Delta h_{\text {turb }}$ in Eqn. 6), equal to the specific work transfer from the rotor wheel. Since it eventually leads to gas flow stagnation temperature loss, the boundary will be referred as a - non-adiabatic pressure loss boundary. The continuity equation remains unchanged from the APL device in Eqn. 3 since the mass flow rate is always conserved across the boundary.

$$
\begin{aligned}
& h_{0}=h_{1}+\frac{u_{1}^{2}}{2}=h_{2}+\frac{u_{2}^{2}}{2}+\Delta h_{\text {turb }} \quad \text { or } \\
& a_{0}^{2}=a_{1}^{2}+\frac{\kappa-1}{2} u_{1}^{2}=a_{2}^{2}+\frac{\kappa-1}{2} u_{2}^{2}+(\kappa-1) \Delta h_{\text {turb }}
\end{aligned}
$$

The pressure loss coefficient through a pressure loss boundary can be defined as [38]:

$$
K=\frac{\kappa \cdot \Delta p}{\rho_{1} u_{1}^{2}}
$$

Further defining the non-adiabatic parameter, $d$ which consists of the stagnation enthalpy transfer term, $\Delta h_{\text {turb }}$ as:

$$
d=\frac{2 \Delta h_{\text {turb }}}{a_{2}^{2}} M_{2}^{2}
$$


It is shown in Appendix A that while simultaneously fulfilling the pressure and stagnation enthalpy loss, an unique boundary upstream Mach number, $M_{1}$ at particular flow condition may be obtained by solving:

$$
M_{1}^{2}=\{2 K(b+d)+a \alpha\}-\frac{\sqrt{\{2 K(b+d)+a \alpha\}^{2}-4(b+d)\left\{(b+d) K^{2}-\alpha\right\}}}{2\left\{(b+d) K^{2}-\alpha\right\}}
$$

$$
\text { where } \quad a=\frac{2}{\kappa-1} \quad b=a M_{2}^{2}+M_{2}^{4} \quad \alpha=\left(\frac{F_{1}}{F_{2}}\right)^{2}
$$

Note that when there is no stagnation enthalpy change across the device, i.e., an adiabatic flow process across the boundary $(d=0)$, Eqn. 10 becomes identical to that in the APL boundary condition formulation [38, 47]. From the derivation in Appendix A, the resultant boundary reflected and transmitted wave characteristics are respectively defined as:

$$
\begin{aligned}
& \lambda_{\text {out }_{1}}=A_{\mathrm{A}_{1}}\left(A_{1}^{*}-\frac{\kappa-1}{2} U_{1}^{*}\right) \\
& \lambda_{\text {out }_{2}}=A_{\mathrm{A}_{2_{\mathrm{c}}}}\left(A_{2}^{*}-\frac{\kappa-1}{2} U_{2}^{*}\right)
\end{aligned}
$$

The parameter with asterisk superscript are those further normalized by their corresponding entropy level, $A_{\mathrm{A}}$. The flow direction through the boundary can be identified via comparing the upstream and downstream incoming flow characteristics, ${ }^{5}$ i.e.,

\footnotetext{
${ }^{5}$ Arbitrarily chosen initially, and corrected if necessary once flow direction has been established.
} 


$$
\begin{aligned}
\text { Positive flow } & \lambda_{\mathrm{in}_{1}}^{*}>\lambda_{\mathrm{in}_{2}}^{*} \\
\text { Reverse flow } & \lambda_{\mathrm{in}_{1}}^{*}<\lambda_{\mathrm{in}_{2}}^{*} \\
\text { No flow } & \lambda_{\mathrm{in}_{1}}^{*}=\lambda_{\mathrm{in}_{2}}^{*}
\end{aligned}
$$

Note that the mathematical calculation of the NAPL boundary is compatible for reverse flow by switching the boundary upstream and downstream stations. However, the experimental turbine reverse flow characteristic is rarely present, hence it is not possible to validate it here. Nevertheless, since the typical turbine upstream pressure is constantly higher than atmospheric, this will not raise additional concern. Even if intermittent reverse flow occurred (e.g., during pulse flow conditions), the associated pressure loss coefficient would achieve a very large magnitude (corresponding to low $M_{2}$, which will be presented in the subsequent section), i.e., consistent with reverse flow through the rotor wheel. Thus the flow direction is expected to resume its conventional direction once the inlet PR has increased above atmospheric. During no flow conditions, the pipe domain flow characteristics will not be updated, i.e., the flow does not experience any change. The instantaneous actual power extracted by the turbine at each time step is then computed via:

$$
\dot{W}_{\mathrm{act}}=\dot{m}_{1} \cdot \Delta h_{\mathrm{turb}}
$$

234 The solution procedure for the NAPL boundary is identical to the APL formulation described in [38], thus can be summarized by the generalized 
form given in Fig. 3 (in reference to equations in Appendix A). At a particular time step, the solution for Eqn. 10 can be found through an incremental search across a range of $M_{2}$ where the convergence is expected to occur, gradually refining its range after each pass of sub-iteration.

[Figure 3 about here.]

\subsection{Solution for pressure loss $\&$ non-adiabatic parameter}

The pressure loss coefficient, $K$ for an APL boundary is typically characterized against the boundary upstream Reynolds number or downstream Mach number at different solidities, ${ }^{6}$ which are obtained empirically from steady flow testing [38]. For a turbocharger turbine, a similar solution has been shown possible [48] and the pressure loss coefficient curves are grouped according to turbine reduced operation speeds, $N_{\mathrm{s}}$, as shown in Fig. 4a. Likewise, the enthalpy change, $\Delta h_{\text {turb }}$ in the non-adiabatic parameter, $d$ of the NAPL boundary can be characterized against the empirical steady-flow performance data from which it will be instantaneously interpolated according to local flow conditions prior to pulsatile operation.

[Figure 4 about here.]

Since the pressure loss coefficient, $K$ and non-adiabatic parameter, $d$ are both functions of the flow state and turbine operating speed, their influence on the new flow state can be summarized as in Fig. 5.

\footnotetext{
${ }^{6}$ The ratio of blocked area to the total cross-sectional area exposed to gas flow at the boundary.
} 
[Figure 5 about here.]

The steady-state calibrated boundary data for the subject single-entry nozzleless turbine is shown in Fig. 4. The calibration procedure involved incrementally searching for the unique combination of pressure loss coefficient, $K$ and stagnation enthalpy loss, $\Delta h_{\text {turb }}$ that would match the steady-flow performance within tolerance. The pressure loss coefficient, without the consideration of enthalpy change across the rotor boundary [37], has been plotted in Fig. 4a to give a sense of how the inclusion of the non-adiabatic parameter affects the turbine model flow state. It is apparent in the non-adiabatic process, for a given turbine PR, the downstream Mach number is always lower than that calculated assuming an adiabatic process, and the difference increases with turbine PR (higher $M_{2}$ ). This is because the loss in gas flow stagnation enthalpy further reduces the gas flow energy. Nonetheless, the shifted Mach number points still fall on a unique speed line curve, which corresponds to the turbine MFP-PR characteristic at that particular speed.

In order to account for different operating temperatures to which the turbine rotor may be subjected, the calibrated specific enthalpy change for the non-adiabatic parameter is further reduced by the boundary upstream stagnation temperature, $T_{01}$. The resultant reduced specific enthalpy change at different turbine operating speeds is shown in Fig. 4b. Note that this reduced specific enthalpy change is analagous to the power parameter used in typical quasi-steady turbine models [38]. A separate hot flow steadystate simulation is also performed in Section 3 to validate this normalization method, by comparing the turbine non-dimensional performance parameters. 


\subsection{Meanline integration method}

Throughout this paper, the new model predictions will be constantly compared against the established meanline integration method prediction [37] apart from the experimental data. For this reason, this methodology will be briefly discussed in this section. The meanline integration method uses the same model domain as in Fig. 1. Similar to the previous section, the subscripts 1 and 2 here denote the rotor boundary upstream and downstream stations respectively. From the converged flow state at the rotor boundary, the meanline integration method first obtains the "averaged" flow condition among the four rotor entries in Fig. 1, i.e.,

$$
\begin{aligned}
& \dot{m}_{1}=\sum_{\text {entry }=0}^{4} \dot{m}_{\text {entry }} \\
& p_{1}=\sum_{\text {entry }=0}^{4} \frac{F_{\text {entry }}}{F_{1}} p_{\text {entry }} \\
& T_{1}=\sum_{\text {entry }=0}^{4} \frac{\dot{m}_{\text {entry }}}{\dot{m}_{1}} T_{\text {entry }}
\end{aligned}
$$

The rotor inlet velocity is then constructed, from which the rotor incidence and passage losses will be considered according to the formulation in $[49,50]$, respectively defined as 


$$
\begin{aligned}
& L_{\text {incidence }}= \begin{cases}\frac{1}{2} K_{\text {incidence }}\left(W_{1} \sin \beta^{\prime}\right)^{2} & \text { if } \quad \beta^{\prime}<\frac{\pi}{4} \\
\frac{1}{2} K_{\text {incidence }} W_{1}^{2}\left(\frac{1}{2}+\left|\beta^{\prime}\right|-\frac{\pi}{4}\right) & \text { if } \quad \beta^{\prime} \geqslant \frac{\pi}{4}\end{cases} \\
& L_{\text {passage }}=\frac{1}{2} K_{\text {passage }}\left[W_{1}^{2} \cos ^{2}\left(\left|\beta_{1}-i_{\text {opt }}\right|\right)+W_{2}^{2}\right] \\
& \text { where } \quad \beta^{\prime}=\beta_{1}-\beta_{\text {blade } 1}-i_{\text {opt }} \\
& \text { and } \quad i_{\text {opt }}=\tan ^{-1}\left[\frac{-1.98 \cdot \tan \theta_{1}}{Z(1-1.98 Z)}\right]
\end{aligned}
$$

The turbine instantaneous actual power in this case is evaluated from the velocity triangle changes across the rotor boundary minus the clearance loss (due to rotor tip clearance) [51] and disk friction loss (the viscous loss between rotating rotor and stationary volute) [52], i.e.,

$$
\begin{aligned}
& \dot{W}_{\text {act }}=\dot{m}_{1}\left(U_{1} C_{\theta_{1}}-U_{2} C_{\theta_{2}}\right)-\left(L_{\text {clearance }}+L_{\text {disk friction }}\right) \\
& L_{\text {clearance }}=\frac{\left(U_{1} C_{\theta_{1}}-U_{2} C_{\theta_{2}}\right) \frac{\text { clearance gap }}{r_{2_{\text {tip }}}}}{1-\frac{r_{2_{\text {hub }}}}{r_{2_{\text {tip }}}}} \\
& L_{\text {disk friction }}=\frac{0.02125 \cdot U_{1}^{2} \rho_{1}^{2}}{\dot{m}_{1}\left(\frac{\rho_{1} U_{1} r_{1}}{\mu}\right)^{0.2}}
\end{aligned}
$$

\section{Steady-state Performance Validation}

Comparison of the steady-state cold-flow turbine swallowing capacity, MFP and actual output power, $\dot{W}_{\text {act }}$ predictions against experimental data is given in Fig. 6. The meanline integration method predictions are the same as those presented in previous works $[36,37]$. The comparison between the 
turbine MFP predictions (evaluated using Eqn. 25) generated by the NAPL boundary and the meanline integration method is given in Fig. 6a.

$$
\mathrm{MFP}=\frac{\dot{m}_{1} \sqrt{T_{01}}}{p_{01}}
$$

Both methods show good agreement with the experimental data with an inaccuracy of less than $5 \%$ throughout a wide range of operating PR and different turbine operating speeds. For the actual power prediction in Fig. 6b, the meanline method showed larger deviation from the experimental data at the lower turbine operating speed $(27.0 \mathrm{rps} / \sqrt{\mathrm{K}})$ since the rotor passage loss coefficient was only calibrated at $43.0 \mathrm{rps} / \sqrt{\mathrm{K}}$ turbine speed. This suggests that the turbine losses experience smaller changes towards higher operating speeds as compared to lower speeds. This observation is also consistent with the calibrated reduced specific enthalpy curves in Fig. 4b for the NAPL boundary method where the 43.0 and $53.7 \mathrm{rps} / \sqrt{\mathrm{K}}$ curves lie closer to one another than the $27.0 \mathrm{rps} / \sqrt{\mathrm{K}}$ speed. The NAPL boundary method on the other hand, showed no deviation larger than $\pm 5 \%$ throughout all steady-state simulation cases since it was calibrated at all three operating speeds.

[Figure 6 about here.]

The hot-flow steady-state simulation was also performed to identify the validity of the characterized reduced specific enthalpy (Fig. 4b) at a different operating temperature. A turbine upstream stagnation temperature of $700 \mathrm{~K}$ is used in the hot-flow steady-state simulations (instead of $\sim 340 \mathrm{~K}$ in coldflow conditions). Since only the turbine aerodynamic performance will be 
examined here, it is assumed the turbine operates under adiabatic conditions (i.e., without external heat transfer as if it is perfectly insulated) despite working under hot gas flow conditions. With such an assumption, the turbine non-dimensional parameters (viz., MFP and total-static efficiency) will equal those for cold flow conditions.

The turbine MFP, mass flow rate, total-static efficiency and the actual power are presented in Fig. 7 in comparison to the cold-flow predictions and experimental data. The turbine non-dimensional mass flow parameter, MFP is identical (Fig. 7a) regardless of the operating temperature, yet the hot-flow mass flow rate is expectedly lower than under cold-flow operation (Fig. 7b). The lower mass flow rate is due to the lower gas flow density at the higher temperature, and the mass flow variation against operating temperature is governed by the non-dimensional MFP. Likewise, the actual output power at hot-flow conditions is also comparably higher than during cold-flow operation (Fig. 7d), yet its ratio to the gas flow isentropic power - the total-static efficiency between different operating temperatures is exactly alike (Fig. 7c). The hot-flow simulation indicated that the calibrated turbine performance parameters at the rotor boundary (Fig. 4) are capable of accounting for different turbine operating temperatures, which is crucial during on-engine simulation.

[Figure 7 about here.]

\section{Pulse Flow Performance Prediction}

The unsteady turbine model pulse flow performance predictions will now be presented at four pulse flow frequencies $(20-80 \mathrm{~Hz})$ at $27.0,43.0$ and 53.7 
rps $/ \sqrt{\mathrm{K}}$ turbine speeds. The unsteady turbine model predictions will be compared to the pulsating flow experimental data [39] and the predictions by the meanline integration method [37].

Fig. 8 shows the comparison of the turbine instantaneous mass flow rate predictions by both the NAPL boundary and meanline integration methods against the experimental data at $20-80 \mathrm{~Hz}$ pulse flow and at all three turbine operating speeds. The magnitude of the mass flow pulses is higher at higher turbine operating speeds. At a glance, both the NAPL boundary and the meanline integration methods deliver equally good mass flow rate predictions with the primary fluctuation magnitude and pulse phase matched reasonably well with the experimental data. A similar trend can be observed at all pulse frequencies.

[Figure 8 about here.]

The comparison of the instantaneous actual power prediction between the NAPL boundary and the meanline integration method against the experimental data is shown in Fig. 9. Again, the predictions by both methods are fairly similar, in terms of actual power magnitude and pulse features. Crucially, the NAPL boundary is also capable of capturing the actual energy transfer phase into the rotor wheel. Note that the instantaneous actual power curves in Fig. 9 are illustrated in their as-recorded phase, i.e., without any phase-shifting. This will appear to be out-of-phase to the instantaneous mass flow curves in Fig. 8. Similar to the mass flow curve, the magnitude of the actual power pulses increase with turbine operating speed. Nonetheless, there are a few noticeable discrepancies between these two predictions, e.g., 
the slight difference in the secondary fluctuation and its features (markedly at $130-190^{\circ}$ pulse cycle at the higher turbine operating speed in Fig. 9). The temporal fluctuations seen in the meanline prediction (around $30-60^{\circ}$ pulse cycle) at higher pulse flow frequency and turbine speed are not visible in the curve from the NAPL boundary method, nor in the experimental data.

[Figure 9 about here.]

Both prediction methods also showed similar a departure trend from the experimental data, i.e., the actual power primary peak at $53.7 \mathrm{rps} / \sqrt{\mathrm{K}}$ speed. Such a mismatch is probably due to the fact that the flow component approaching the rotor is no longer operating in a quasi-steady manner at this operating range. From meanline method analysis [37], it was discovered that the rotor upstream absolute flow angle remained largely constant throughout the pulse cycle which was somewhat inconsistent with the relevant CFD findings [53] which showed the rotor upstream absolute flow angle changing up to $20^{\circ}$. In order to capture this flow phenomenon, the tangential velocity (swirl) component must be modelled separately, which is only possible via the two-dimensional modelling mentioned earlier in Section 2.1, and is out of scope of this work. After all, the model developed here is to be incorporated into a conventional one-dimensional engine gas dynamics code, hence the consistent gas dynamics governing equations set (Eqns. 1 and 2) has been maintained, as well as its dimension.

The instantaneous predictions in Figs. 8 and 9 can be further quantified as prediction deviation density plots in spectral form, to assess the prediction quality with regards to the empirical data and between prediction methods. 
The instantaneous mass flow rate and actual power prediction deviations $\left(\dot{m}_{\text {dev }}\right.$ and $\dot{W}_{\text {dev }}$ ) are computed using Eqns. 26 and 27 respectively. The prediction deviations are normalized by the maximum mass flow/actual power of the corresponding operating condition since the pulse magnitude varies according to operating speed and pulse flow frequency. The density plots of model prediction deviation are shown in Figs. 10 and 11. The abscissa shows the percentile of the deviation whereas the ordinate represents the number (density) of instantaneous prediction points falling within a particular deviation range. To give a sense of the prediction performance at different operating speeds and pulse frequencies, the histograms in Figs. 10 and 11 are further broken down into operating speed and pulse frequency constituents.

$$
\begin{aligned}
& \dot{m}_{\text {dev }}(\%)=\frac{\dot{m}_{\text {pred }}-\dot{m}_{\text {exp }}}{\dot{m}_{\text {exp }_{\text {max. }}}} \times 100 \% \\
& \dot{W}_{\text {dev }}(\%)=\frac{\dot{W}_{\text {act }}{ }_{\text {pred }}-\dot{W}_{\text {actexp }}}{\dot{W}_{\text {actexp } \max .}} \times 100 \%
\end{aligned}
$$

[Figure 10 about here.]

[Figure 11 about here.]

The distribution plots of instantaneous mass flow rate prediction deviation given in Fig. 10 for the meanline and the NAPL boundary methods are highly comparable. In fact, the mean \pm standard deviation $\left(\overline{\dot{m}_{\mathrm{dev}}} \pm \sigma_{\dot{m}_{\mathrm{dev}}}\right)$ for the meanline and the NAPL boundary prediction methods are $1.4 \% \pm 8.2 \%$ and $0.8 \% \pm 8.3 \%$ respectively. Since this is a percentage error, the ideal value would be nil, meaning no deviation from experimental results. In this case, 
the NAPL boundary method yielded a lower deviation of mean at $0.8 \%$ as compared to the $1.4 \%$ resulting from the meanline integration method. Another aspect of this data is the standard deviation, which provides a sense of the spread of this error percentage. Fig. 10 shows that the instantaneous mass flow deviations from the experimental data given by both solution methods have a comparable spread. It can also be seen that the mass flow rate prediction quality across different operating speeds and pulse frequencies are also fairly consistent between both prediction methods, illustrated by the more or less similar histogram sub-section height and their distribution pattern between Fig. 10a and 10b.

Similar considerations as the mass flow can be made for the instantaneous actual power prediction (Fig. 11). The mean \pm standard deviation $\left(\overline{\dot{W}_{\text {dev }}} \pm \sigma_{\dot{W}_{\text {dev }}}\right)$ for the meanline and the NAPL boundary predictions methods are $1.9 \% \pm 13.5 \%$ and $0.8 \% \pm 12.8 \%$ respectively. Again, the mean prediction deviation from the NAPL boundary method showed slightly higher adherence to the experimental data than the meanline integration method, i.e., $0.8 \%$ against $1.9 \%$. The spread of instantaneous actual power prediction points are generally wider than for the mass flow prediction in Fig. 10, owing to the mismatch of the actual power peak at higher turbine speeds illustrated in Fig. 9. Nevertheless, due to lesser tertiary fluctuation at these pulse peaks in the NAPL boundary method, the deviation spread in Fig. 11b is marginally narrower (12.8\%) than the meanline method (13.5\%) from their corresponding means. Fig. 11 also shows that the actual power prediction performance of both the NAPL boundary and meanline integration methods are comparable at different pulse frequencies and turbine speeds, indicated 
by the largely similar histogram sub-section heights and their distribution pattern between Figs. 11a and 11b.

The histogram distribution in Figs. 10 and 11 have been found not to follow a normal distribution via a normality test particularly towards the tail ends of the distribution curve, thus limiting the validity of any further statistical analyses that may be performed. Nevertheless, such a highly populated deviation plot around zero deviation is still a good indication of turbine model performance. Furthermore the NAPL boundary method formulated in this paper, i.e., a relatively simple method of achieving an unsteady turbine model in a conventional one-dimensional engine gas dynamic code, has been shown to deliver highly similar predictions to the meanline integration method - a more theoretical method of evaluating turbocharger turbine actual power yet more tedious and sophisticated to accomplish.

Another important comparison aspect to be taken into consideration is the amount of model inputs required by the meanline integration and NAPL boundary methods. Table 2 summarizes the performance parameter and geometrical information needed in setting up the unsteady turbine models using these two boundary methods. In both methods, the steady-flow performance maps (for model performance tuning/rotor boundary characterization) and volute geometry along azimuth angle (for constructing the domain in Fig. 1) are mandatory. While the NAPL boundary method requires only the rotor inducer and exducer flow area (in order to define the boundary area ratio, $\alpha$ in Eqn. 10), the meanline integration method demands more detailed rotor dimensions (i.e., blade number, angles, diameters and clearance gap as indicated in the lower-half of Table 2) in order to evaluate the four losses under 
consideration (Eqns. 20-24). Hence, the comparisons in Table 2 and Figs. 811 indicate that the NAPL boundary method can be a more favourable choice in achieving the same quality of pulse flow prediction without the need for extensive rotor geometry measurements.

\section{[Table 2 about here.]}

\subsection{Unsteady pressure propagation}

Fig. 12 shows the unsteady pressure wave propagation along the model domain (using the NAPL boundary method) at $43.0 \mathrm{rps} / \sqrt{\mathrm{K}}$ turbine speed for the $20-80 \mathrm{~Hz}$ pulse flow cases. Instantaneous static pressure is recorded at eight locations along the model domain, viz., turbine inlet, $0^{\circ}, 45^{\circ}, 90^{\circ}, 135^{\circ}$, $180^{\circ}, 225^{\circ}$ and $270^{\circ}$ azimuth angle. The mean/cycle-averaged static pressure for each pulse frequency case at these particular locations is also given in the legend of each subplot. In general, it can be seen that the pulse flow shape and magnitude experiences the largest change between the turbine inlet and $45^{\circ}$ azimuth angle (from Figs. 12a to 12b), with the mean static pressure remaining nearly constant throughout the remainder of the turbine volute with a small gradual drop in its magnitude.

At higher pulse frequency, the magnitude of the secondary peak becomes closer to the primary pulse as the gas flow travels further downstream into the turbine volute due to the associated wave action activity. Such observation shows that the nozzle-shaped volute amplifies the pulse magnitude as the gas flow cross-sectional area gradually gets smaller. This also helps to explain the presence of the strong secondary peak beyond $120^{\circ}$ pulse cycle in the experimental measurement plane mass flow profile at $80 \mathrm{~Hz}$ flow while the 
test facility rotary pulse generator $[8,9,39]$ only generates one triangular pulse within each $0-360^{\circ}$ pulse cycle. It is worth mentioning that the finding in Fig. 12 is also in line with the experimental instantaneous volute pulsating pressure traces reported in [11].

\section{[Figure 12 about here.]}

The realistic wave action prediction indicates that the combination of the turbine model domain (in Fig. 1) and the NAPL rotor boundary is capable of capturing the major flow structures within the turbocharger turbine under pulsating flow. Such a model capability is indispensable during engine simulation since any pressure (wave) reflections from the rotor boundary and volute domain will affect the back pressure (restriction) on the engine model.

\section{Computation time comparison}

Although it has been shown, from a prediction quality perspective, that the NAPL boundary method can be an effective substitute for the meanline integration method in evaluating the unsteady turbine actual power, it is still worthwhile to analyse the feasibility of solving the difficulty of the meanline integration method mentioned in Section 1.1 in the future work. For this assessment, the computational time performance of these two methods will be compared, i.e., another vital criterion of an effective unsteady turbine model in an engine gas dynamic code, since engine model analyses are typically performed transiently.

The computational time comparison will emphasize the time required in obtaining the boundary pressure loss coefficient and non-adiabatic parameter 
since the remaining computational steps (updating the flow field characteristics and flow propagation in the turbine domain) are identical regardless of which method is used. The computing time comparison is carried out for three different turbine steady-state constant pressure ratios $(\mathrm{PR}=1.3$, 1.6 and 1.9$)$ at $43.0 \mathrm{rps} / \sqrt{\mathrm{K}}$ turbine operating speed. In this way, the rotor upstream tangential velocity in the meanline integration method can be evaluated easily without any conflict in the phase-difference. Different PR operating points will result in different flow states across the rotor boundary; hence the actual computation time is expected to be slightly different.

Fig. 13 presents the actual averaged computing time for the meanline and the NAPL boundary methods executed on a conventional desktop workstation. The averaged values are taken over five computation cycles (time steps). The focus here is on the relative computing time difference between these methods, labelled as percentile in Fig. 13. In general, the NAPL boundary requires approximately $38.6 \%$ less computational time compared to the meanline integration method, and the difference becomes larger towards lower operating $\mathrm{PR}$ (to as much as $44.6 \%$ at $\mathrm{PR}=1.3$ ). The longer computational time of the meanline method is due to its procedural step in solving the meanline loss equations (Eqns. 20-24) which consist of several implicit iterations whereas for the NAPL boundary method, the procedure involves only the linear interpolation in obtaining the reduced specific enthalpy change and pressure loss coefficient data from Fig. 4. Such a difference in computing time is not negligible considering that one-dimensional gas dynamic simulations are often transient and the time step can be rather small ${ }^{7}$ depending on the

\footnotetext{
${ }^{7}$ In the case of the pulse flow analyses presented in Section 4, the time step can be as
} 
model domain complexity. Moreover throughout the pulse cycle under studied (which replicates the exhaust pulse flow a turbine may be encountered during on-engine operation), the gas flow PR is at a low magnitude for most instance.

[Figure 13 about here.]

This assessment although brief, has shown that the NAPL boundary method is capable of matching the same level of accuracy of turbine performance prediction as that using the meanline integration method in a shorter computational time. Therefore, the use of the meanline model in engine modelling could be limited to extrapolating the conventionally narrow manufacturer's steady-state turbine maps (such as those practised by [54]). In the occasion where detailed rotor geometrical information is not accessible, a physically-based method of extrapolating turbine performance maps [55] may be used. Instead of typical polynomial-based methods employed in conventional engine simulations, these turbine map extrapolation methodologies provide a more physically realistic trend of turbine performance variation particularly towards very low and high PR range. The broadened steady-flow performance maps can then be used in characterizing the NAPL boundary (i.e., obtaining the pressure and enthalpy loss curves in Fig. 4) for engine transient simulation use.

\section{Conclusion}

In this study, the following conclusions may be drawn:

small as $1 \mathrm{~ms}$. 
1. A non-adiabatic pressure loss (NAPL) boundary has been formulated for evaluating the pulse flow turbocharger turbine actual power as an alternative to the meanline integration method reported in previous study [37].

2. The formulation of the NAPL boundary is based on the adiabatic counterpart, but with the inclusion of a turbine work transfer - gas flow stagnation enthalpy loss term.

3. The unsteady turbine model is calibrated against steady-flow performance data, and the non-dimensionality of boundary data has been verified via hot steady-flow simulation.

4. The NAPL boundary method showed highly comparable predictions with the meanline integration method and experimental data at different pulse flow frequencies and operating speeds. This is despite the simplification of not evaluating the turbomachinery losses in real-time, but relying on instantaneous interpolation of the pre-characterized boundary data.

5. As such, the NAPL boundary method required less computational time compared to the meanline integration method - by $38.6 \%$ on average.

6. The NAPL boundary method required significantly less rotor geometrical inputs in comparison to the meanline integrated method. This enhanced the overall model applicability.

7. The pulse pressure trace in the model domain closely resembles the literature empirical data trend [11], thus confirming the validity of the finite unsteady turbine model domain in resolving the physical wave action taking place in pulsating flow conditions. 
8. It is suggested that the systematic use of numerical turbine models in engine simulation codes will be possible by using the conventional meanline model/physical-based extrapolation method to broaden the conventionally narrow turbocharger turbine steady-flow maps (instead of the typical numerical extrapolation method). The widened performance map can then be used to obtain the unsteady model boundary data/parameter (as described in this paper) for on-engine simulation.

\section{Acknowledgement}

The authors would like to thank Universiti Teknologi Malaysia for the Flagship Grant VOT 01G49. 


\section{Nomenclature}

$a \quad$ speed of sound $(\mathrm{m} / \mathrm{s})$

A dimensionless speed of sound

$A_{\mathrm{A}} \quad$ dimensionless entropy level

C source vector

$C_{\theta} \quad$ rotor tangential velocity

d non-adiabatic term

e $\quad$ specific internal energy $(\mathrm{J} / \mathrm{kg})$

$F \quad$ cross-sectional area $\left(\mathrm{m}^{2}\right)$

F flux vector

G friction source term

$h \quad$ specific enthalpy $(\mathrm{J} / \mathrm{kg})$

$K \quad$ loss coefficient/pressure loss coefficient

$L \quad$ loss

$\dot{m} \quad$ mass flow rate

M Mach number

MFP pseudo-non-dimensional mass flow parameter

$N_{\mathrm{s}} \quad$ dimensionless speed parameter

NAPL non-adiabatic pressure loss

$p \quad$ pressure $(\mathrm{Pa})$

PR pressure ratio

$q \quad$ specific heat transfer rate $(\mathrm{J} / \mathrm{kg} \cdot \mathrm{s})$

$t \quad$ temporal dimension

$T$ temperature $(\mathrm{K})$

$u \quad$ velocity $(\mathrm{m} / \mathrm{s})$

\section{Greek letters}

$\alpha$

$\beta$

$\Delta$

$\kappa$

$\lambda$

$\rho$

$\sigma$

$\theta$

$\mu$

\section{Subscripts}

0

1

2

blade

\section{B}

c

clearance

d

dev

disk friction

entry

$\exp$

hub boundary cross-sectional area ratio

relative flow angle (rad)

increment/changes

ratio of specific heats

Riemann variable

density $\left(\mathrm{kg} / \mathrm{m}^{3}\right)$

standard deviation

absolute flow angle (rad)

gas flow dynamic viscosity total or stagnation value upstream of subject station downstream of subject station parameter associated to rotor blade parameter associated to boundary corrected form of parameter parameter associated to clearance loss derived parameter prediction deviation parameter associated to disk friction parameter associated to rotor entry experimental value dimension at rotor hub 
$U$ dimensionless velocity/rotor tangential velocity in

W state vector

$W \quad$ relative velocity

$\dot{W}_{\text {act }} \quad$ work transfer $(\mathrm{kW})$

$x \quad$ spatial dimension

Z blade number

\section{Superscript}

* $\quad$ values normalized with respect to entropy level tip turb

incoming or incidence parameter

incidence parameter associated to incidence loss

$\max \quad$ maximum value

$\mathrm{n}$

out outgoing or transmitted parameter

passage parameter associated to passage loss

pred prediction value

ref reference value

dimension at rotor tip

parameter associated to turbine 


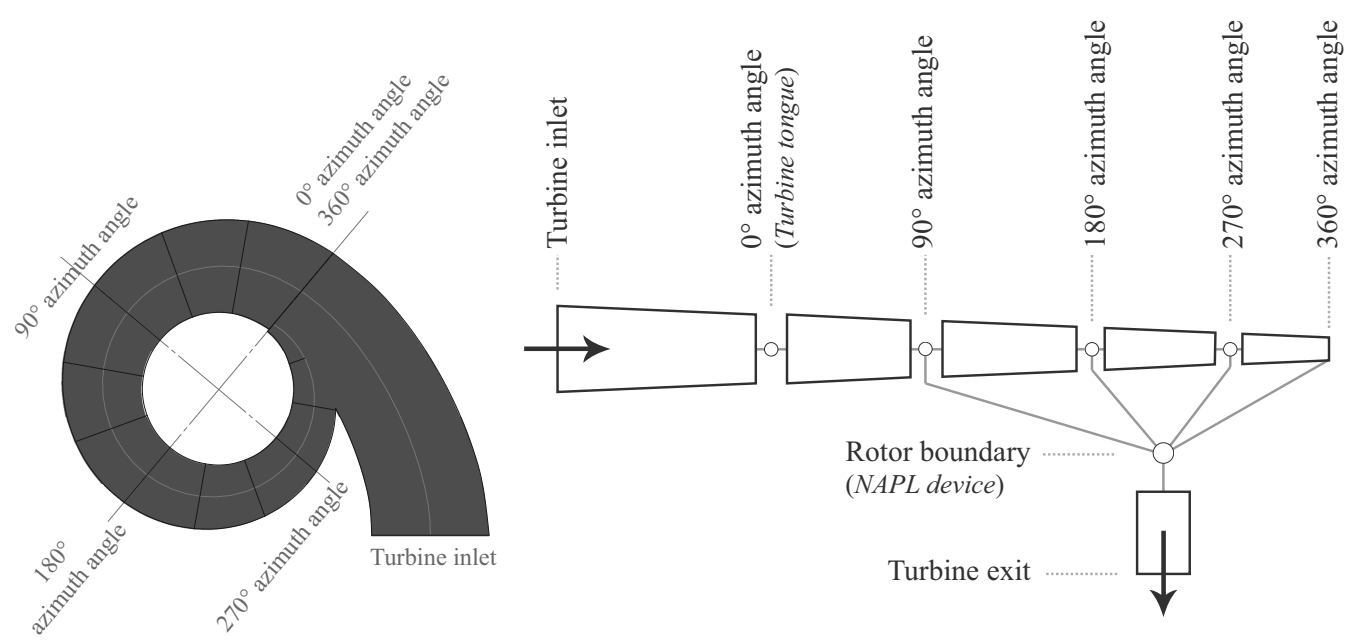

Figure 1: Schematic diagram of the one-dimensional turbine model domain.

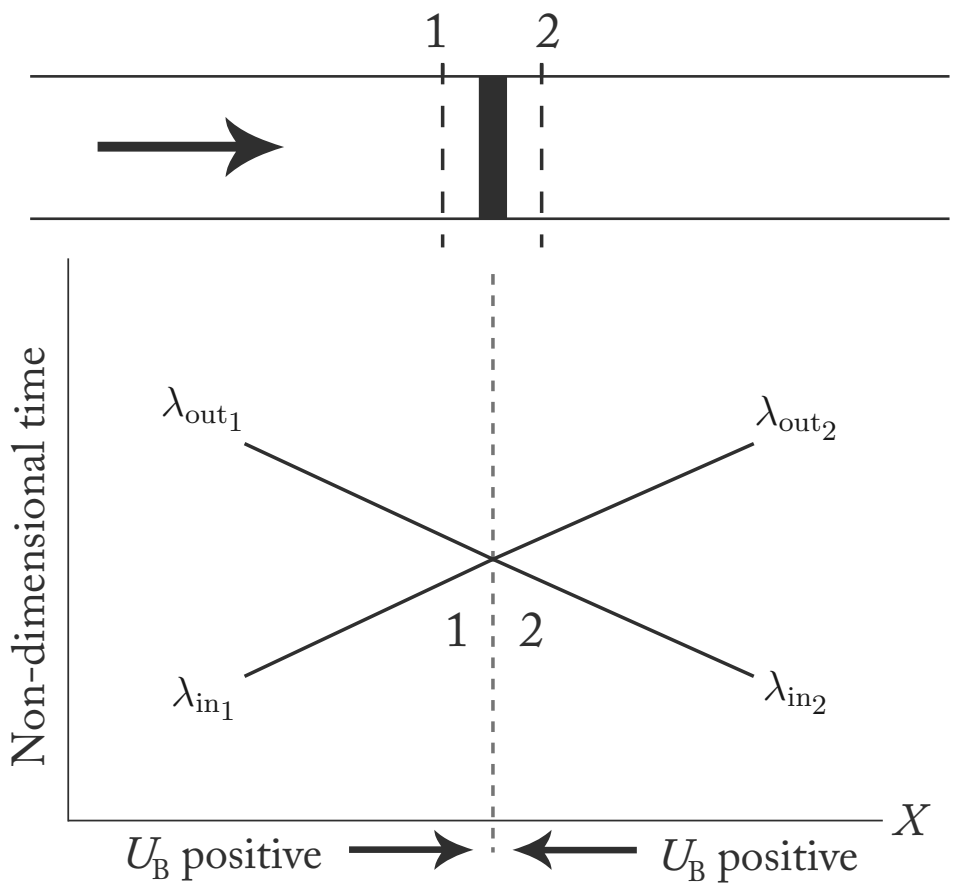

Figure 2: Position diagram of a pressure loss device. 


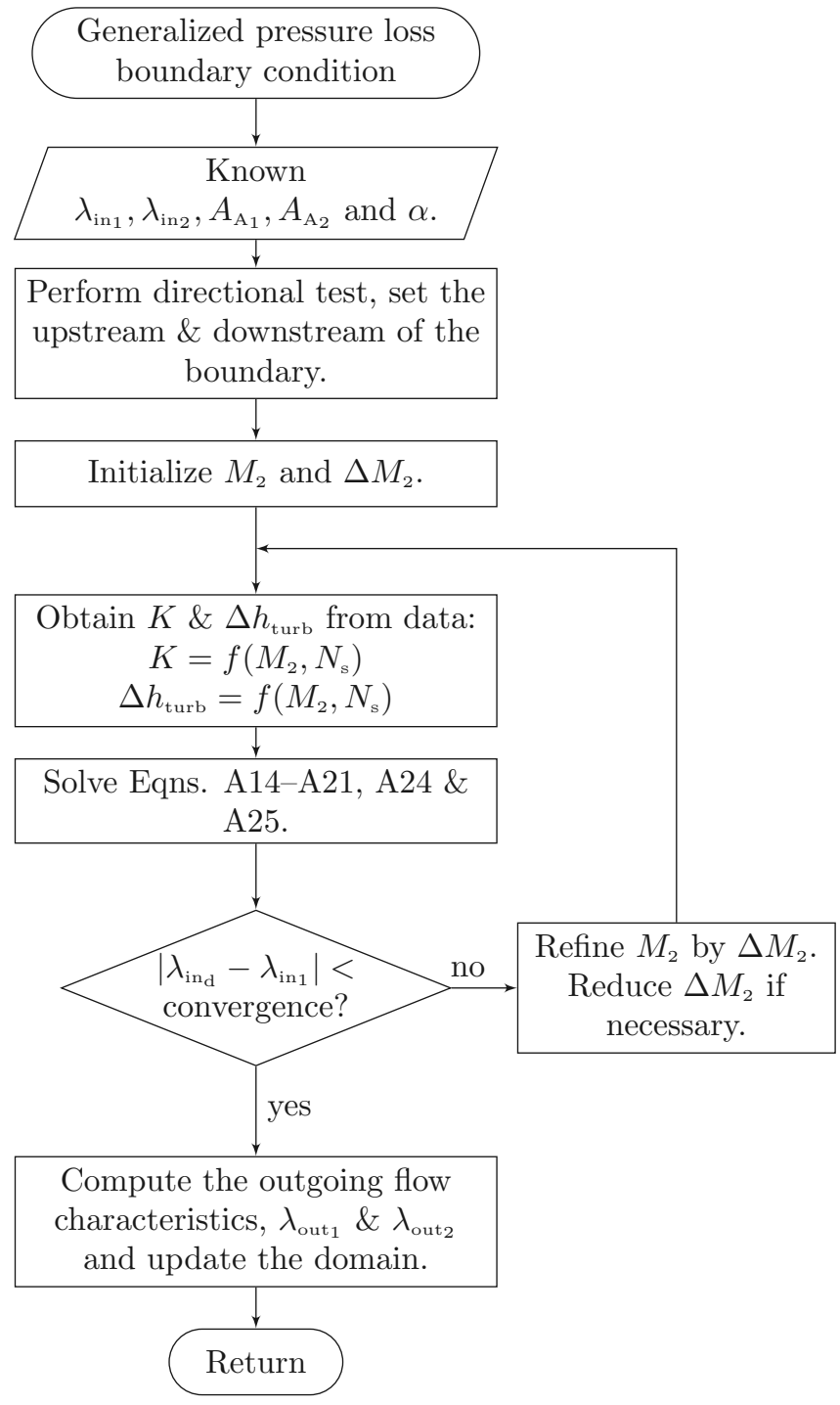

Figure 3: Flow diagram showing the solution procedure for the generalized pressure loss (APL and NAPL) boundary. 


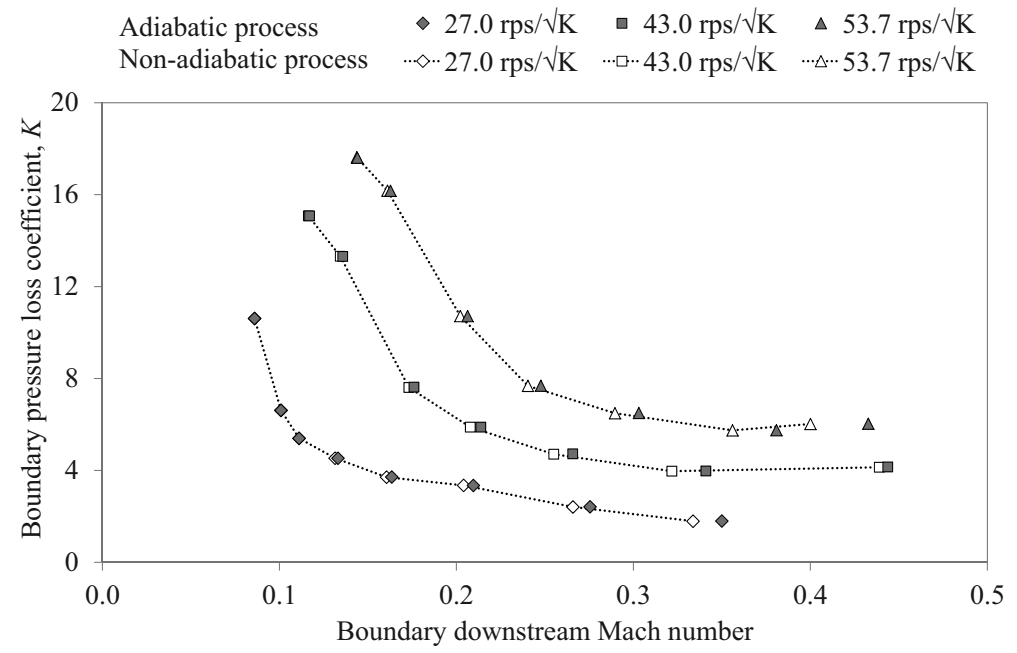

(a)

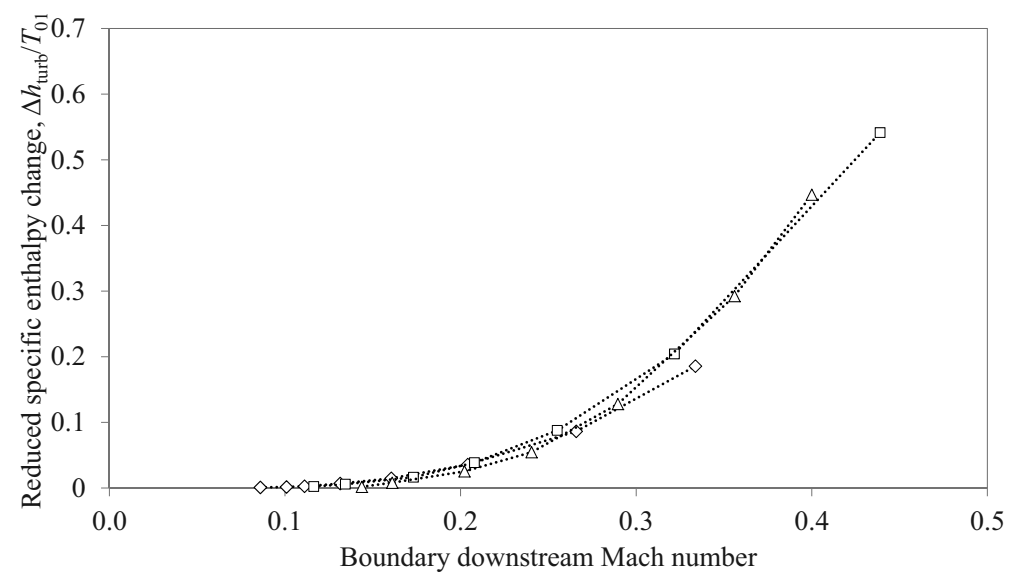

(b)

Figure 4: Calibrated (a) pressure loss coefficient and (b) reduced specific enthalpy change profiles at three turbine operating speeds. 


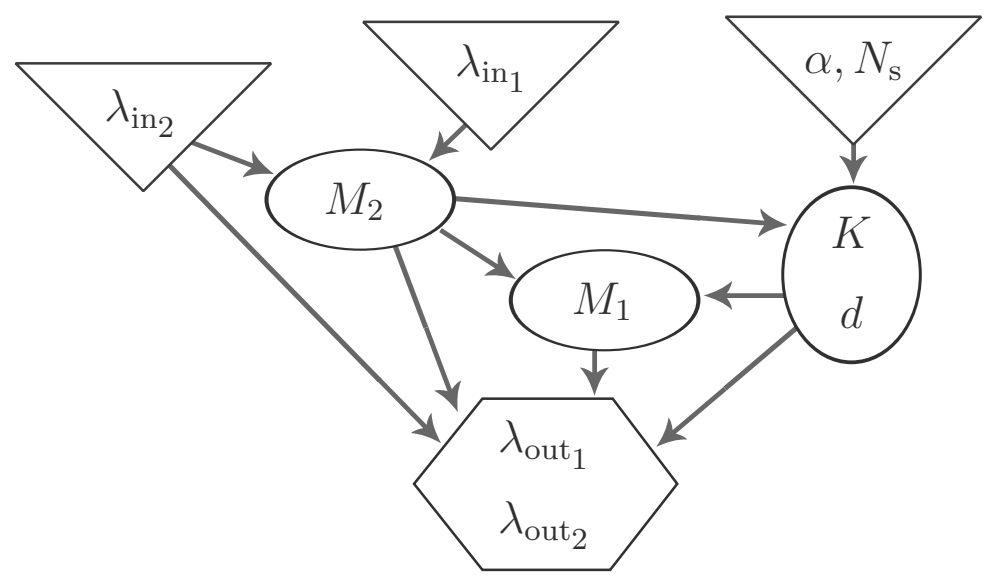

Figure 5: Influence chart showing the relationship between boundary losses, domain existing and new flow states. 


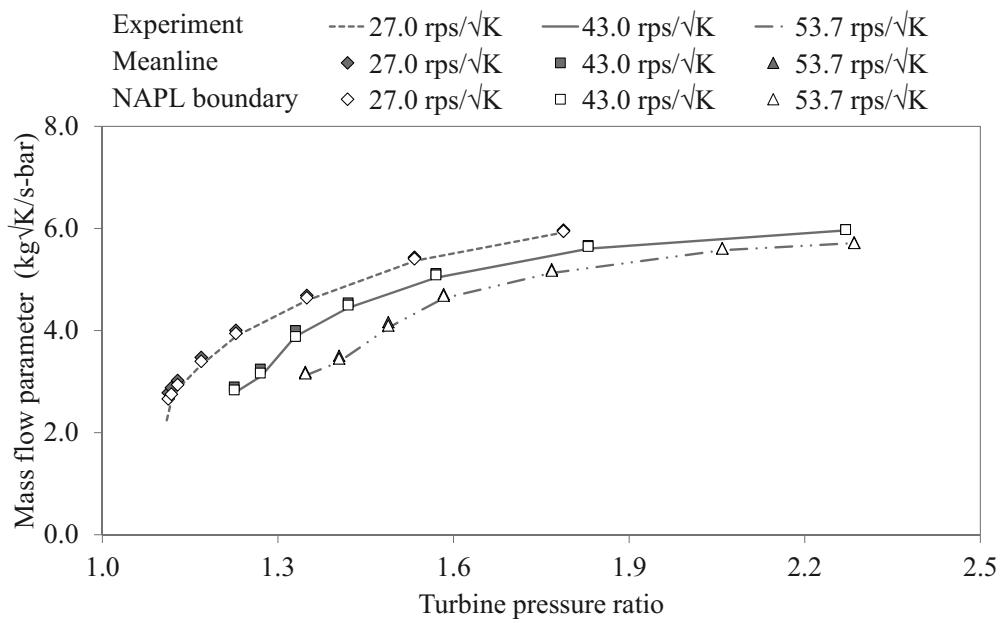

(a)

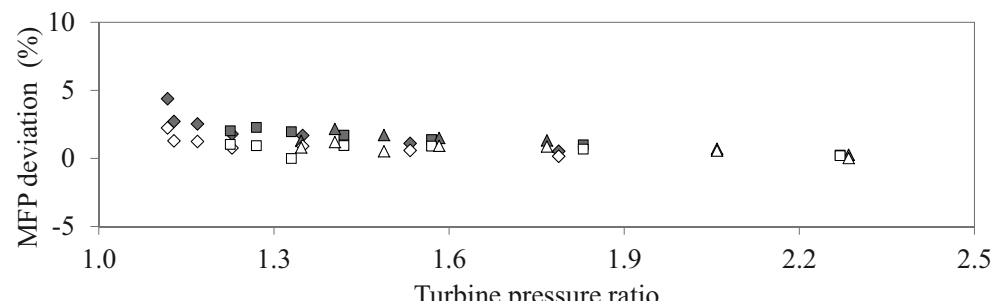

(b)

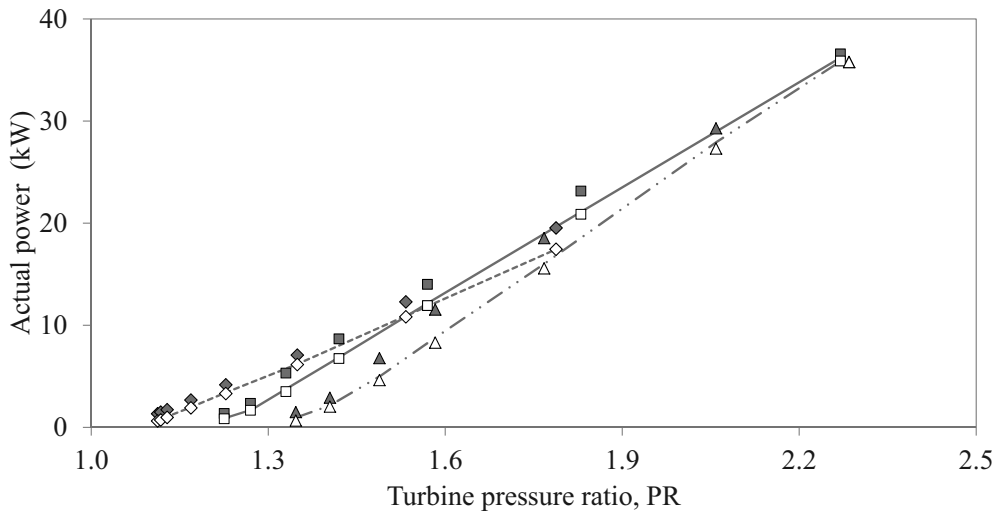

(c)

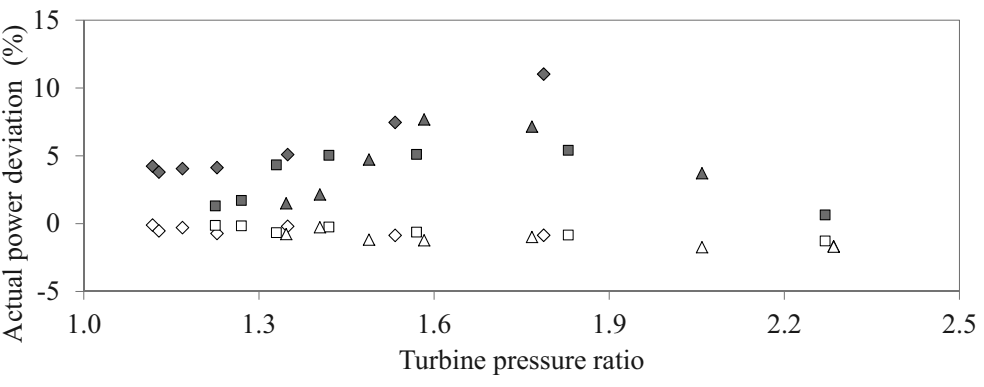

Figure 6: Steady-state turbine (a) MFP and $\{$ h ) corresponding deviations, (c) actual power predictions and (d) the corresponding deviations compared to experimental data plotted against turbine PR. 


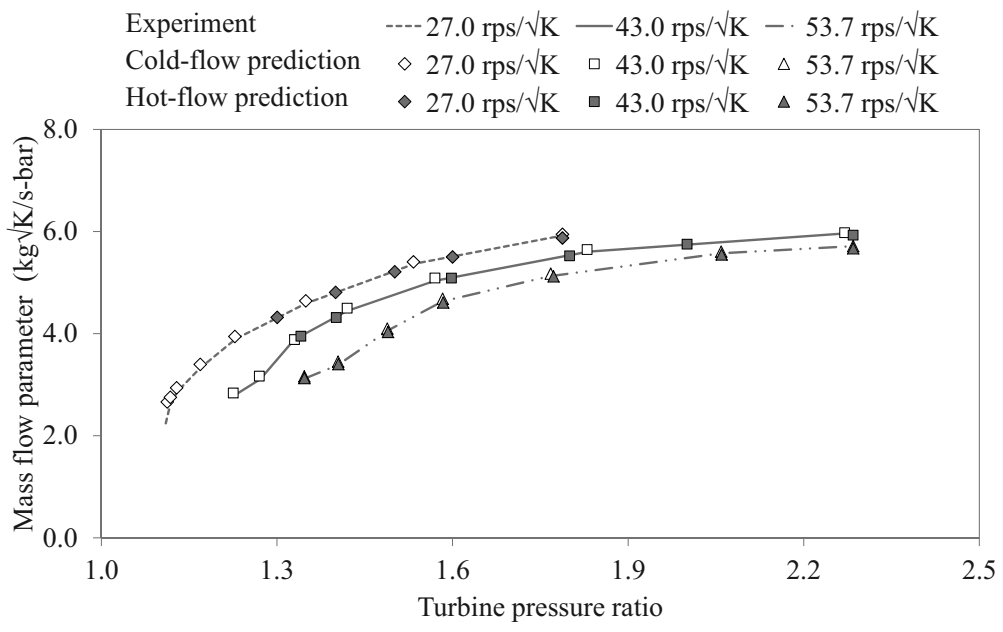

(a)

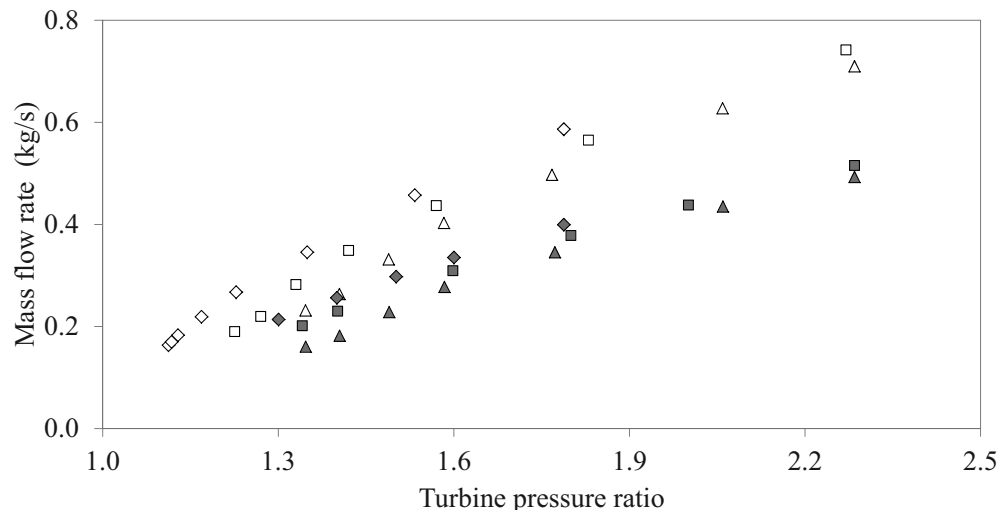

(b)

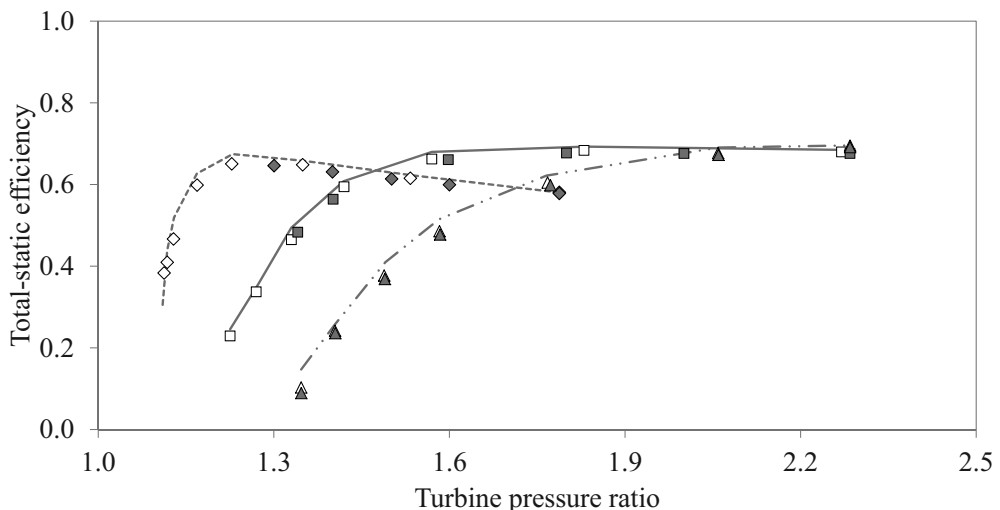

(c)

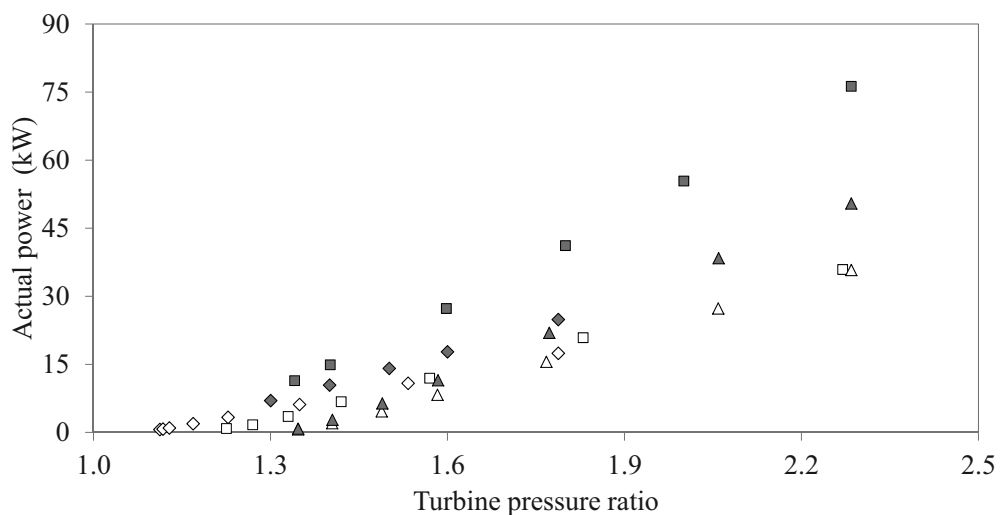

(d)

Figure 7: Steady state turbine (a) MFP, (b g gnass flow rate, (c) total-static efficiency and (d) actual power predictions at hot-flow condition compared to cold-flow experimental data and predictions. 


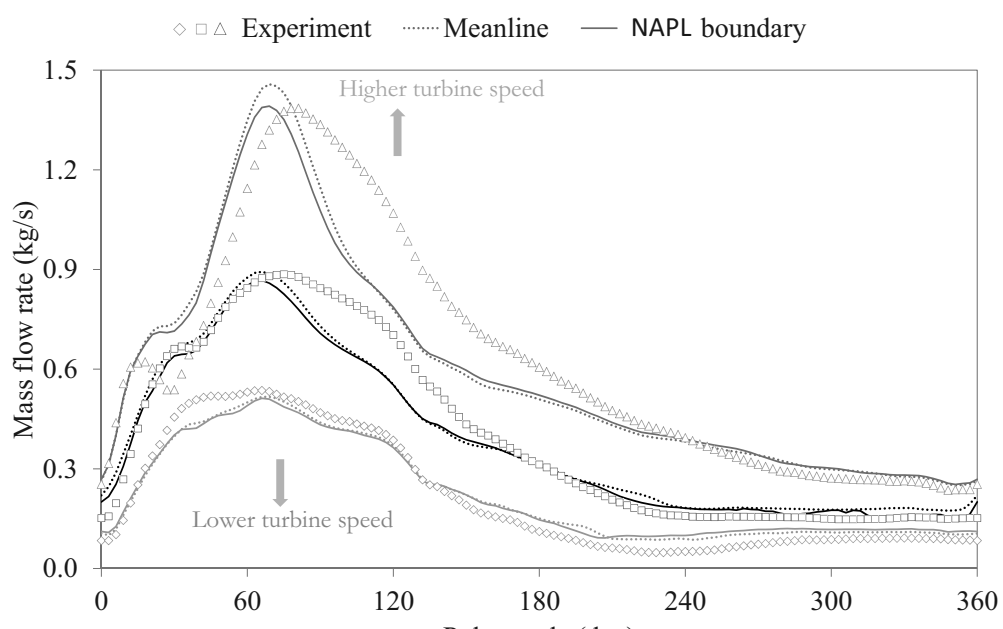

(a)

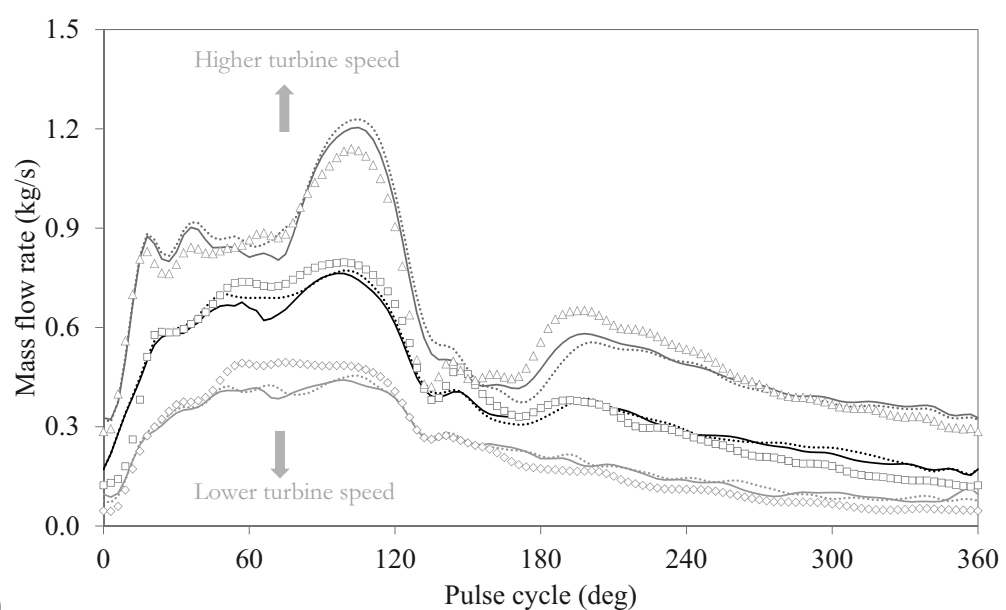

(b)

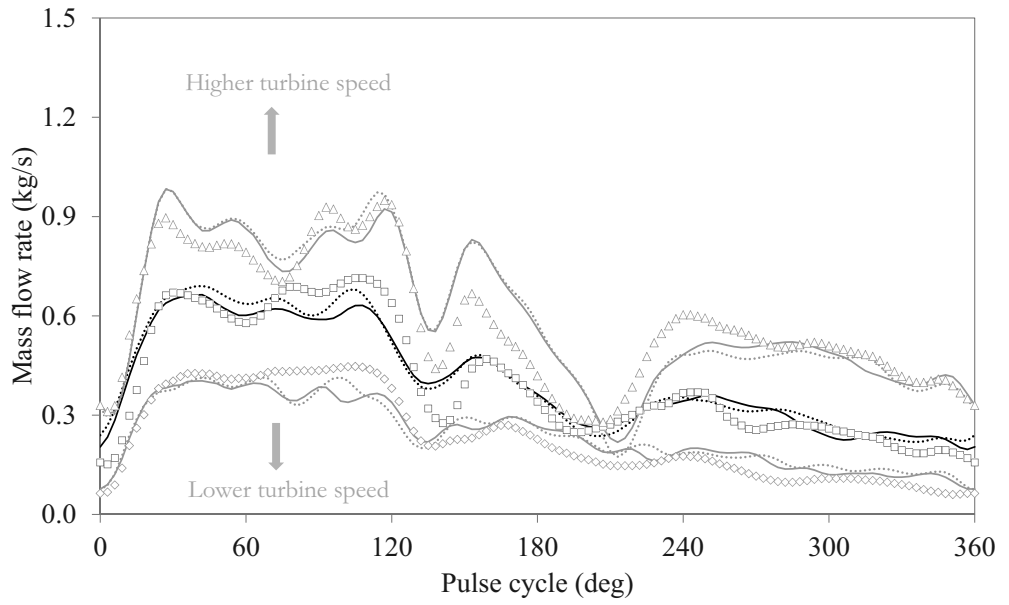

(c)

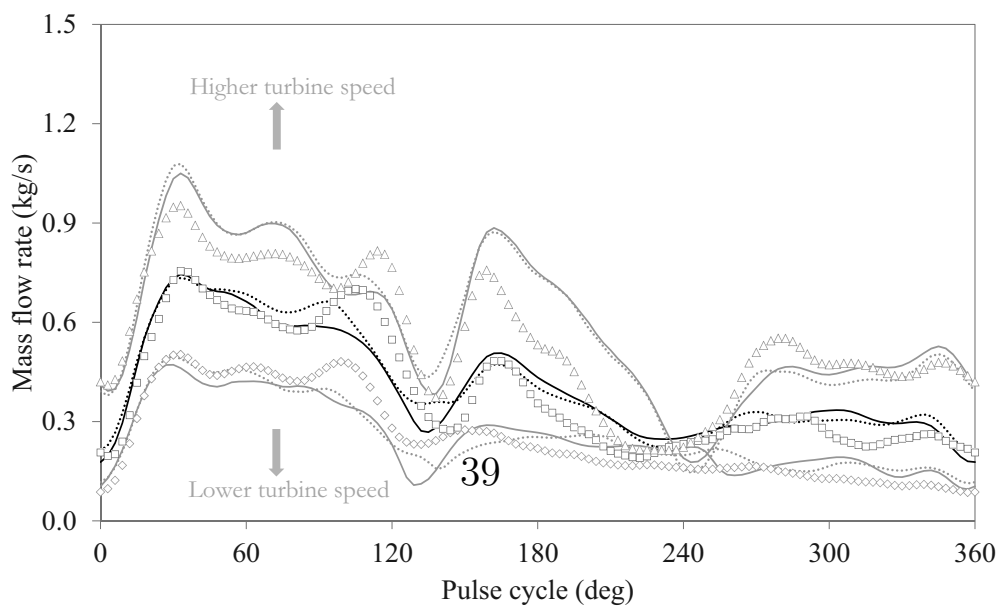

Figure 8: Instantaneous mass flow rate prediction comparison at (a) $20 \mathrm{~Hz}$, (b) $40 \mathrm{~Hz}$, (c) $60 \mathrm{~Hz}$ and (d) $80 \mathrm{~Hz}$ pulse flow. 


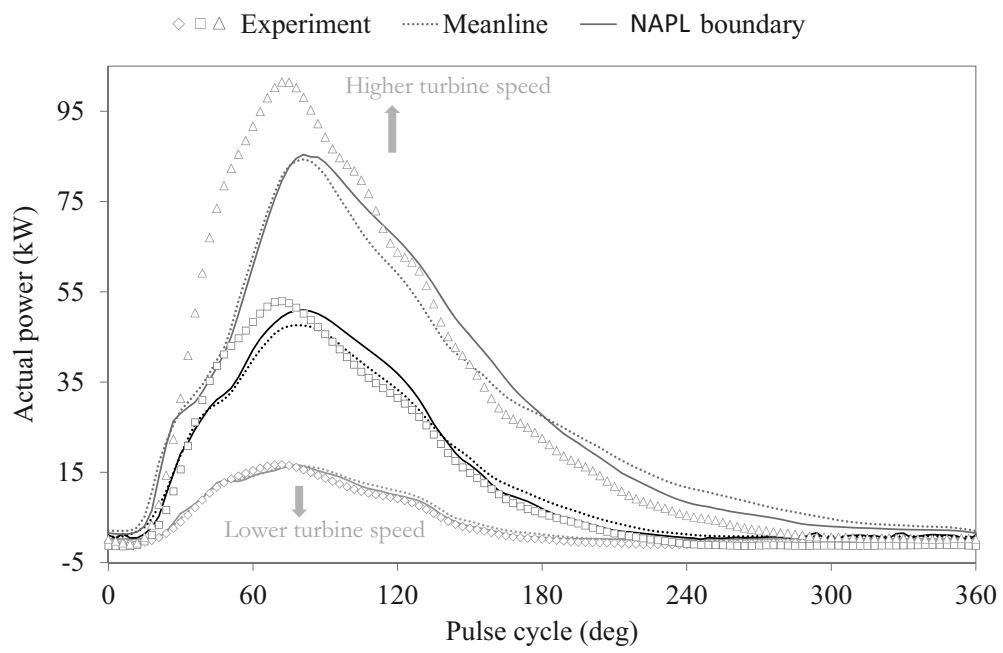

(a)

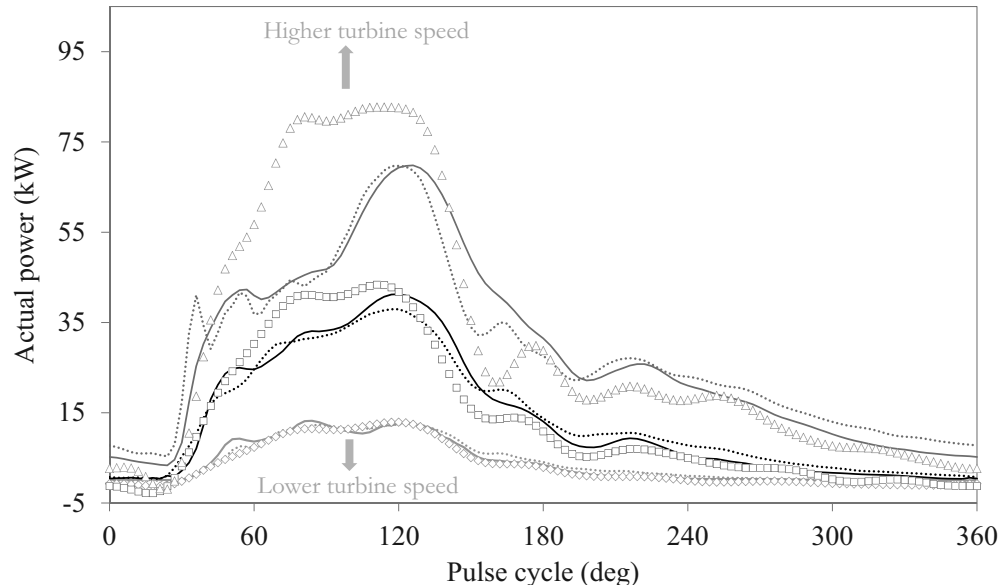

(b)

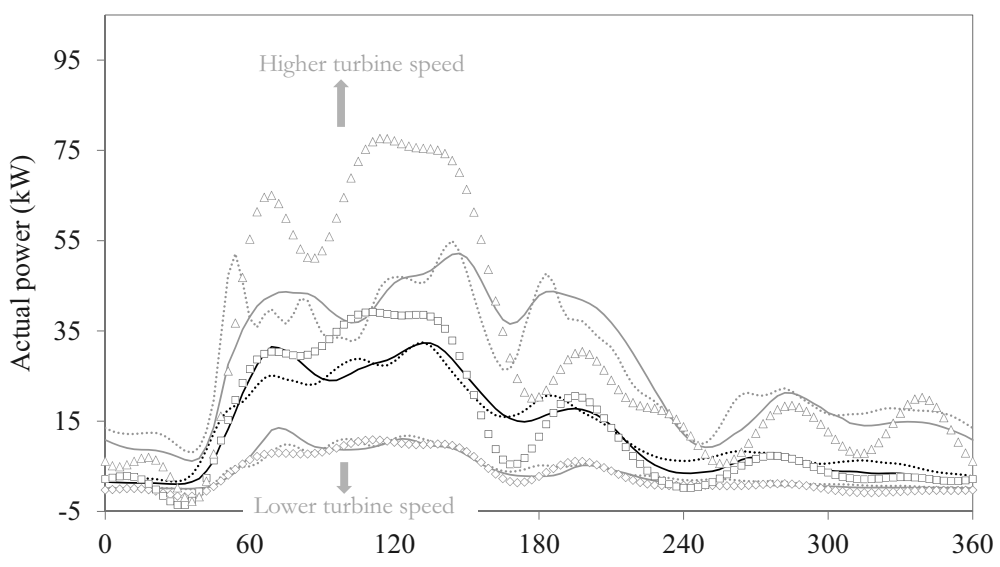

(c)

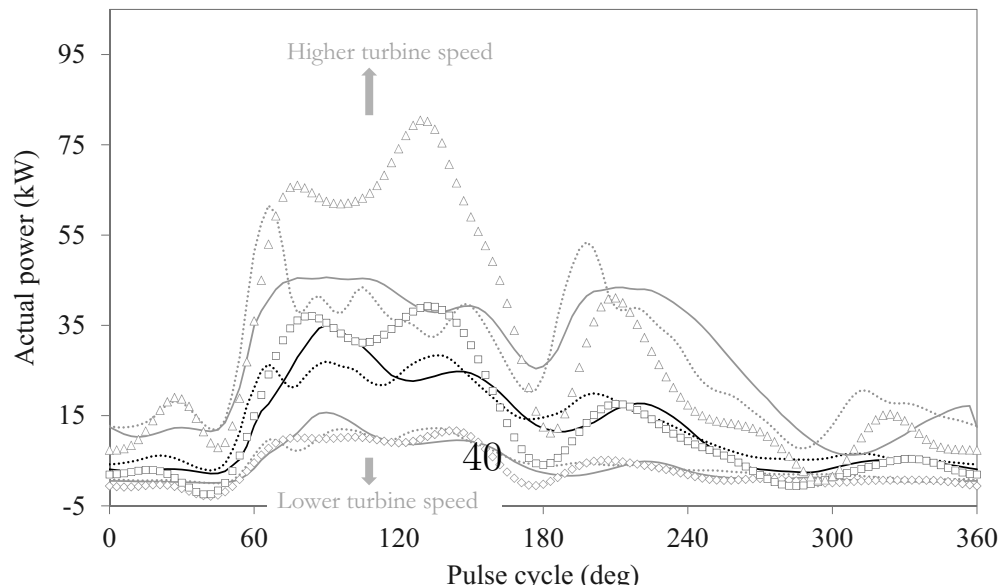

$(\mathrm{d})$

Figure 9: Instantaneous actual power prediction comparison at (a) $20 \mathrm{~Hz}$, (b) $40 \mathrm{~Hz}$, (c) $60 \mathrm{~Hz}$ and (d) $80 \mathrm{~Hz}$ pulse flow. 


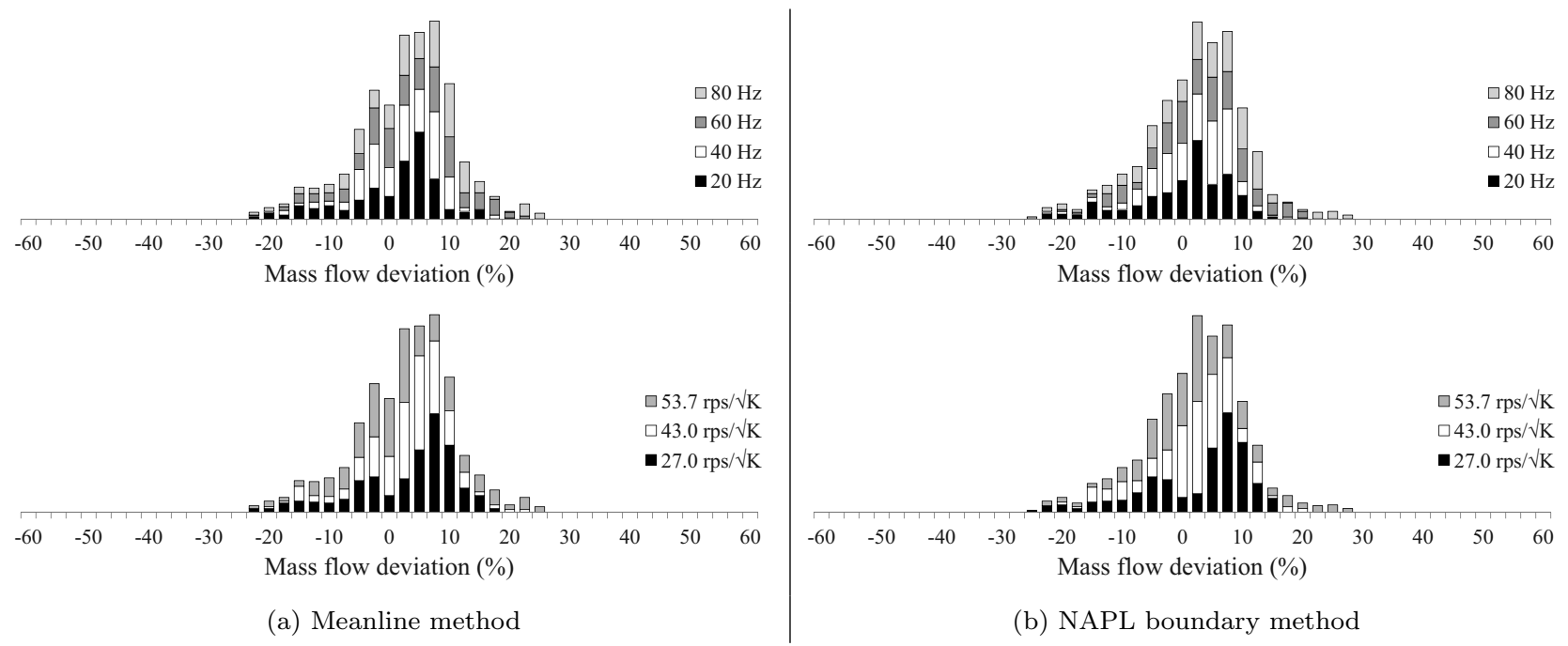

Figure 10: Distribution plot of instantaneous mass flow rate prediction deviation, $\dot{m}_{\mathrm{dev}}$ according to pulse flow frequency and turbine operating speed.

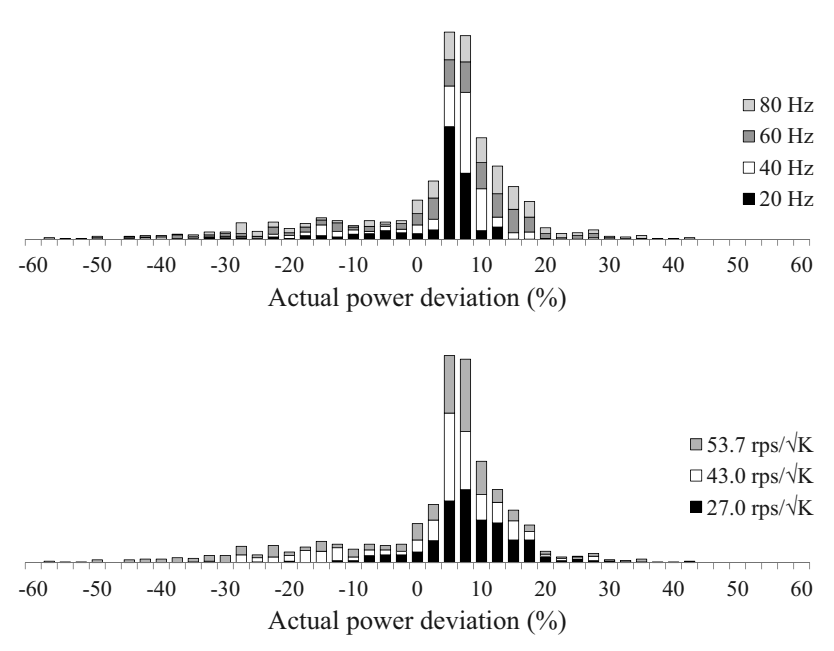

(a) Meanline method

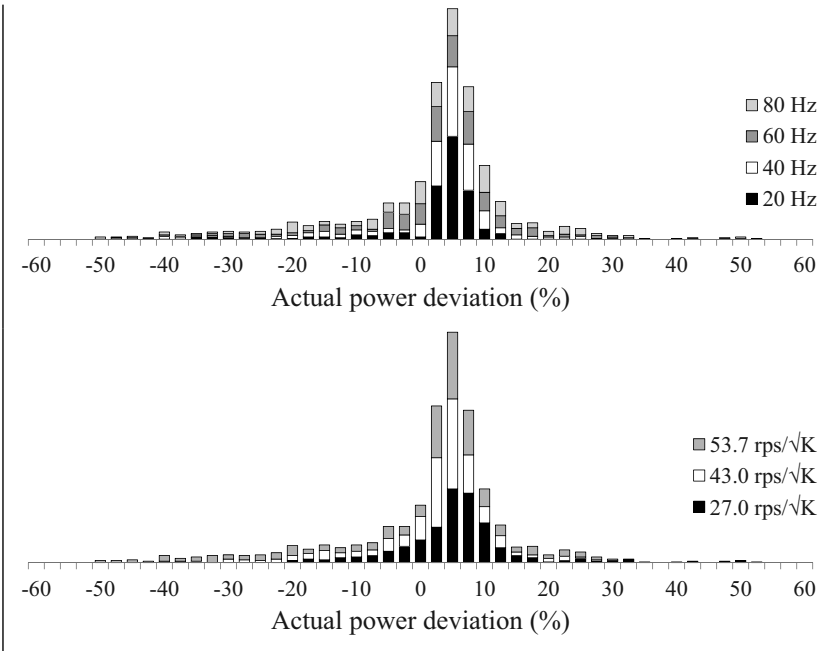

(b) NAPL boundary method

Figure 11: Distribution plot of instantaneous actual power prediction deviation, $\dot{W}_{\mathrm{dev}}$ according to pulse flow frequency and turbine operating speed. 


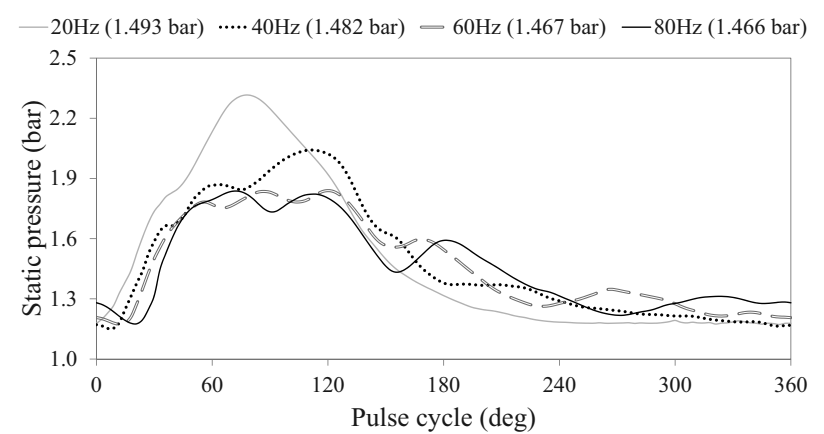

(a)

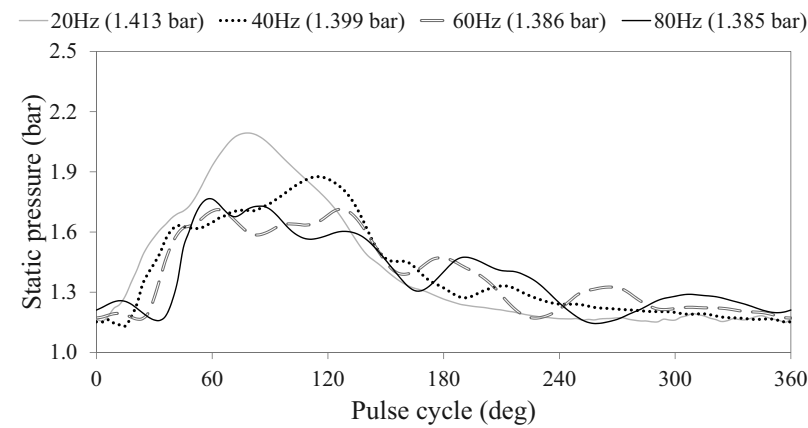

(b)

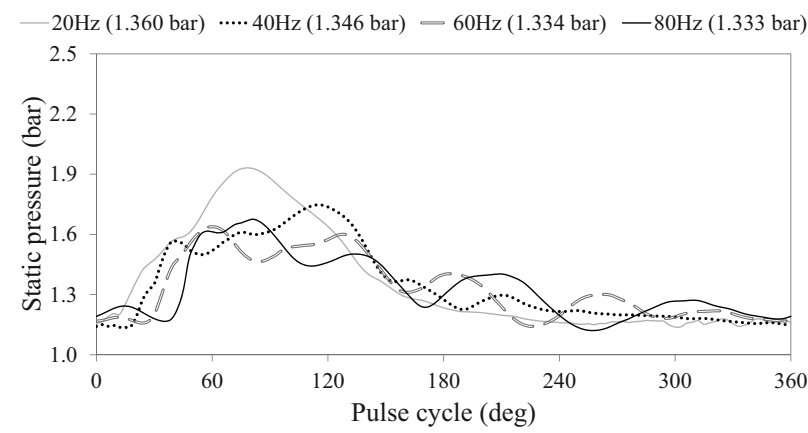

(c)

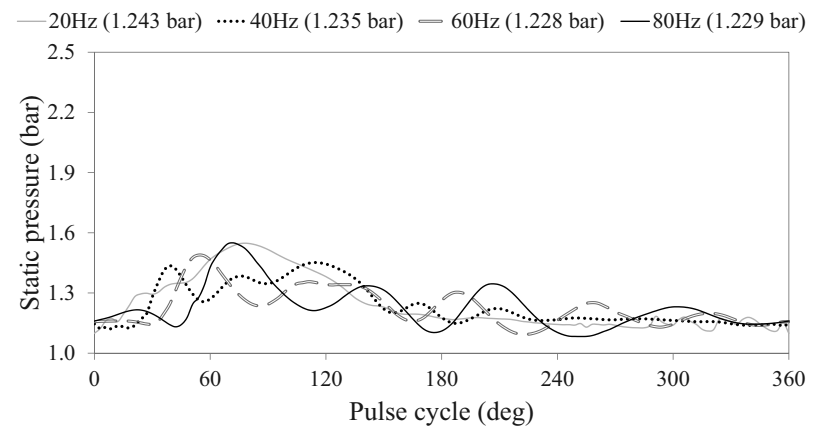

(d)

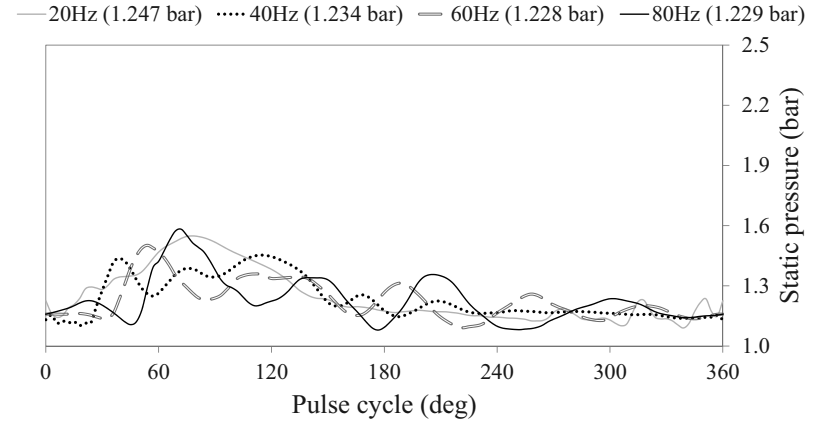

(e)

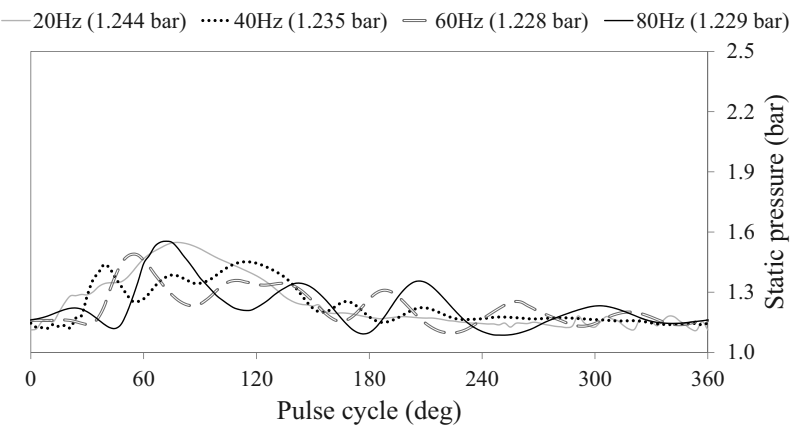

(f)

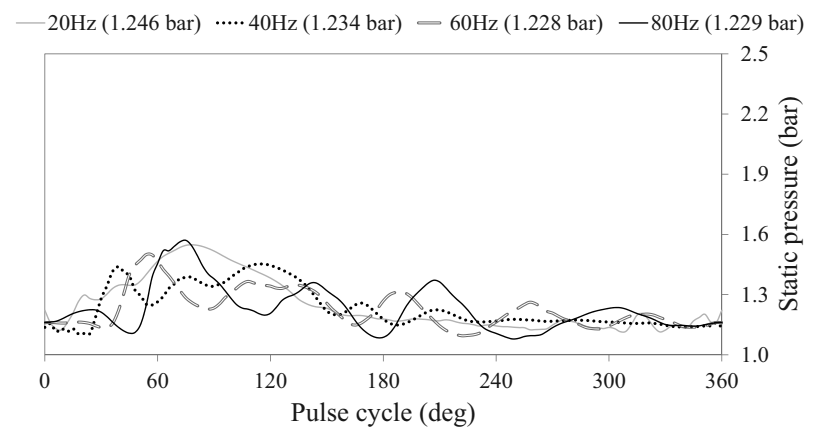

(g)

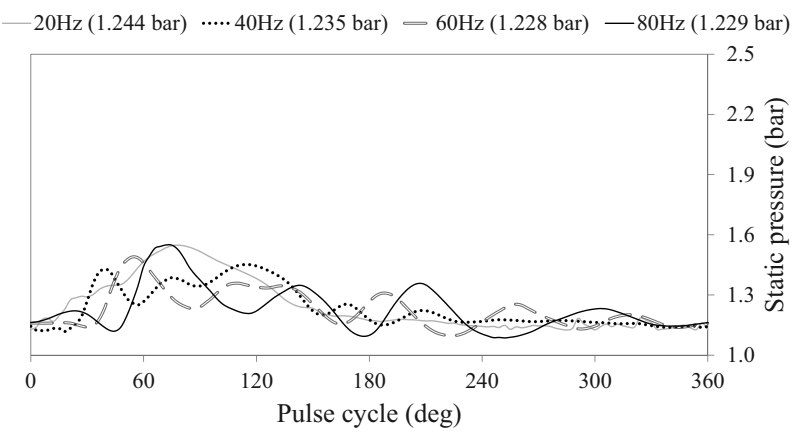

(h)

Figure 12: Pulse pressure distribution around model domain at (a) turbine inlet, (b) $0^{\circ}$, (c) $45^{\circ}$, (d) $90^{\circ}$, (e) $135^{\circ}$, (f) $180^{\circ}$, (g) $225^{\circ}$ and (h) $270^{\circ}$ azimuth angle. 


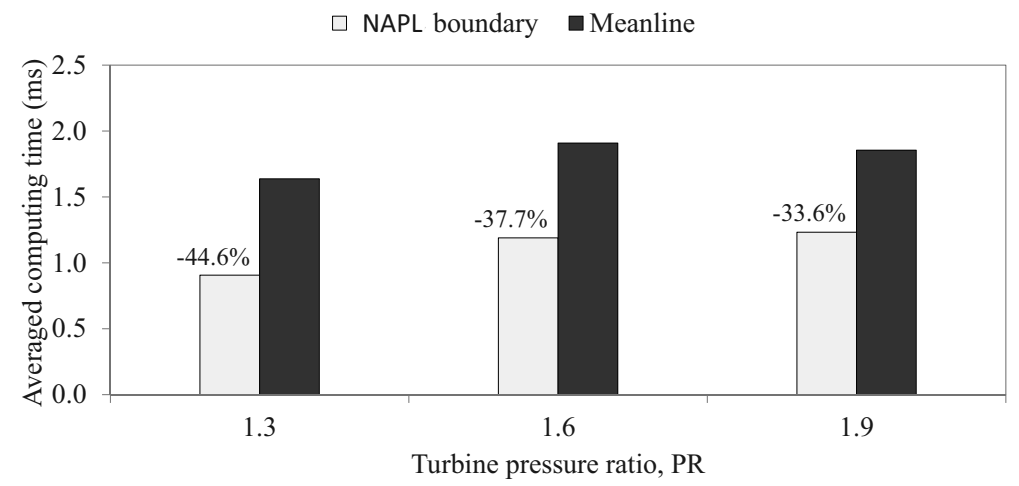

Figure 13: Averaged computation time (in milliseconds) between meanline integration and NAPL boundary methods. 
Table 1: One-dimensional turbine model domain geometry.

\begin{tabular}{lcc}
\hline Location & $\begin{array}{c}\text { Hydraulic diameter } \\
(\mathrm{mm})\end{array}$ & $\begin{array}{c}\text { Cumulative length } \\
(\mathrm{mm})\end{array}$ \\
\hline Turbine inlet & 67.7 & 0 \\
$0^{\circ}$ azimuth & 57.2 & 181.35 \\
$90^{\circ}$ azimuth & 49.1 & 292.95 \\
$180^{\circ}$ azimuth & 41.1 & 397.65 \\
$270^{\circ}$ azimuth & 30.3 & 494.15 \\
$360^{\circ}$ azimuth & 10.5 & 579.15 \\
Turbine exit & 75.0 & 659.15 \\
\hline
\end{tabular}

Table 2: Comparison of model inputs between meanline integration and NAPL boundary method.

\begin{tabular}{lcc}
\hline Rotor boundary method & Meanline integration & NAPL boundary \\
\hline Steady-flow performance & & $\checkmark$ \\
PR vs. MFP map & $\checkmark$ & $\checkmark$ \\
PR vs. Total-static efficiency/ & & \\
actual power map & & \\
& & $\checkmark$ \\
Volute geometry & $\checkmark$ & $\checkmark$ \\
Volute inlet area & $\checkmark$ & \\
Volute exit area & & $\checkmark$ \\
& & $\checkmark$ \\
Rotor geometry & $\checkmark$ & \\
Inducer area & $\checkmark$ & \\
Exducer area & $\checkmark$ & \\
Inducer blade angle & $\checkmark$ & \\
Exducer blade angle & $\checkmark$ & \\
Inducer tip diameter & $\checkmark$ & \\
Exducer tip diameter & $\checkmark$ & \\
Exducer hub diameter & $\checkmark$ & \\
Blade number & $\checkmark$ & \\
Inducer tip-to-shroud clearance & $\checkmark$ & \\
Exducer tip-to-shroud clearance & & \\
V= required & &
\end{tabular}


Continuity equation (Eqn. 3):

$$
\rho_{1} u_{1} F_{1}=\rho_{2} u_{2} F_{2}
$$

Energy equation (Eqn. 5):

$$
a_{0}^{2}=a_{1}^{2}+\frac{\kappa-1}{2} u_{1}^{2}=a_{2}^{2}+\frac{\kappa-1}{2} u_{2}^{2}+(\kappa-1) \Delta h_{\mathrm{turb}}
$$

Pressure loss coefficient (Eqn. 8):

$$
K=\frac{\kappa \cdot \Delta p}{\rho_{1} u_{1}^{2}}
$$

${ }_{596}$ Rearranging energy equation (Eqn. A.2) with Mach number definition $M=\frac{u}{a}$ 597 gives

$$
\left(\frac{a_{1}}{a_{2}}\right)^{2}=\frac{\frac{2}{\kappa-1}+M_{2}^{2}}{\frac{2}{\kappa-1}+M_{1}^{2}}+\left[\frac{2 \Delta h_{\text {turb }}}{a_{2}^{2}} \cdot \frac{1}{\frac{2}{\kappa-1} M_{1}^{2}}\right]
$$

598 599

$$
\frac{p_{2}}{p_{1}}=\frac{F_{1}}{F_{2}} \cdot \frac{a_{2}}{a_{1}} \cdot \frac{M_{1}}{M_{2}}
$$


Rearranging the pressure loss coefficient definition (Eqn. A.3) with the ideal gas definition gives

$$
\begin{aligned}
K & =\left(\frac{p_{1}-p_{2}}{p_{1}}\right) \frac{1}{M_{1}^{2}} \quad \text { or } \\
\frac{p_{2}}{p_{1}} & =1-K M_{1}^{2}
\end{aligned}
$$

Combining Eqns. A.4-A.7 give an expression that relates the boundary upstream and downstream steady flow Mach number to its pressure loss coefficient, $K$, i.e.,

$$
\frac{\frac{2}{\kappa-1}+M_{2}^{2}}{\frac{2}{\kappa-1}+M_{1}^{2}}+\left[\frac{2 \Delta h_{\text {turb }}}{a_{2}^{2}} \cdot \frac{1}{\frac{2}{\kappa-1}+M_{1}^{2}}\right]=\left(\frac{F_{1}}{F_{2}}\right)^{2} \frac{M_{1}^{2}}{M_{2}^{2}\left(1-K M_{1}^{2}\right)^{2}}
$$

Equation A.8 appears in second order polynomial equation form. By simplifying the constant terms (or at least assuming they remain unchanged over a particular time step), the solution for Eqn. A.8 can be expressed as

$$
\begin{aligned}
& M_{1}^{2}=\{2 K(b+d)+a \alpha\}-\frac{\sqrt{\{2 K(b+d)+a \alpha\}^{2}-4(b+d)\left\{(b+d) K^{2}-\alpha\right\}}}{2\left\{(b+d) K^{2}-\alpha\right\}} \\
& \text { where } \quad a=\frac{2}{\kappa-1} \quad b=a M_{2}^{2}+M_{2}^{4} \quad d=\frac{2 \Delta h_{\text {turb }}}{a_{2}^{2}} M_{2}^{2} \quad \alpha=\left(\frac{F_{1}}{F_{2}}\right)^{2}
\end{aligned}
$$

608 The boundary starred Riemann variables, $\lambda_{\mathrm{B}}^{*}$ (flow characteristics normalized by entropy level, $\left.A_{\mathrm{A}_{\mathrm{B}}}\right)$ are defined as

$$
\begin{array}{ll}
\text { Incoming } & \lambda_{\mathrm{in}_{\mathrm{B}}}^{*}=A_{\mathrm{B}}^{*}+\frac{\kappa-1}{2} U_{\mathrm{B}}^{*} \\
\text { Outgoing } & \lambda_{\mathrm{in}_{\mathrm{B}}}^{*}=A_{\mathrm{B}}^{*}-\frac{\kappa-1}{2} U_{\mathrm{B}}^{*}
\end{array}
$$


${ }_{610}$ Equation A.10 can be further rearranged as

$$
\begin{aligned}
& \frac{\lambda_{\mathrm{in}_{\mathrm{B}}}^{*}}{A_{\mathrm{B}}^{*}}=1+\frac{\kappa-1}{2} \frac{U_{\mathrm{B}}^{*}}{A_{\mathrm{B}}^{*}}=1+\frac{\kappa-1}{2} M_{\mathrm{B}} \\
& \text { hence } \quad A_{\mathrm{B}}^{*}=\frac{\lambda_{\mathrm{in}_{\mathrm{B}}}^{*}}{1+\frac{\kappa-1}{2} M_{\mathrm{B}}}
\end{aligned}
$$

${ }_{611}$ Upstream of the boundary, $\mathrm{B}=1 ; M_{\mathrm{B}}=M_{1}$; downstream, $\mathrm{B}=2 ; M_{\mathrm{B}}=$ ${ }_{612}-M_{2}$. Therefore for $\mathrm{B}=2$, the non-dimensional speed of sound (again, 613 normalized against its entropy level) is

$$
A_{2}^{*}=\frac{\lambda_{\mathrm{in} 2}^{*}}{1+\frac{\kappa-1}{2} M_{2}}
$$

${ }_{614}$ Since $A_{1}^{*}=\left(\frac{p_{1}}{p_{\text {ref }}}\right)^{\frac{\kappa-1}{2 \kappa}}$ and $A_{2}^{*}=\left(\frac{p_{2}}{p_{\text {ref }}}\right)^{\frac{\kappa-1}{2 \kappa}}$, hence

$$
A_{1}^{*}=\left(\frac{p_{1}}{p_{2}}\right)^{\frac{\kappa-1}{2 \kappa}} A_{2}^{*}
$$

${ }_{615}$ Combining Eqns. A.6, A.14 and A.15 yields

$$
A_{1}^{*}=\left(\frac{1}{1-K M_{1}^{2}}\right)^{\frac{\kappa-1}{2 \kappa}}\left[\frac{\lambda_{\mathrm{in}_{2}}^{*}}{1-\frac{\kappa-1}{2} M_{2}}\right]
$$

${ }_{616}$ From Eqn. A.4:

$$
\left(\frac{A_{1}}{A_{2}}\right)^{2}=\frac{\frac{2}{\kappa-1}+M_{2}^{2}}{\frac{2}{\kappa-1}+M_{1}^{2}}+\left[\frac{d}{M_{2}^{2}} \cdot \frac{1}{\frac{2}{\kappa-1} M_{1}^{2}}\right]
$$


where

$$
\frac{d}{M_{2}^{2}}=\frac{2 \Delta h_{\text {turb }}}{a_{2}^{2}} \quad \text { and } \quad \frac{A_{1}^{*}}{A_{2}^{*}}=\frac{\frac{A_{1}}{A_{\mathrm{A}_{1}}}}{\frac{A_{2}}{A_{\mathrm{A}_{2}}}}=\frac{A_{1}}{A_{2}} \cdot \frac{A_{\mathrm{A}_{2}}}{A_{\mathrm{A}_{1}}}
$$

$$
A_{\mathrm{A}_{2 \mathrm{c}}}=\left(\frac{A_{\mathrm{A}_{2}}}{A_{\mathrm{A}_{1}}}\right) A_{\mathrm{A}_{1}}
$$

625 The un-corrected boundary downstream inlet characteristic, normalized 626 by the corrected downstream entropy level is given as

$$
\lambda_{\mathrm{in}_{2_{\mathrm{n}}}}^{*}=\frac{\lambda_{\mathrm{in}_{2 \mathrm{n}}}}{A_{\mathrm{A}_{2_{\mathrm{c}}}}}
$$


${ }_{627}$ The remaining normalized flow variables, i.e., $U_{1}^{*}$ and $U_{2}^{*}$ are obtained 628 from

$$
\begin{aligned}
& U_{1}^{*}=M_{1} \cdot A_{1}^{*} \\
& U_{2}^{*}=M_{2} \cdot A_{2}^{*}
\end{aligned}
$$

629 630 631 632

$$
\lambda_{\mathrm{in}_{1_{\mathrm{d}}}}=A_{\mathrm{A}_{1}}\left(A_{1}^{*}+\frac{\kappa-1}{2} U_{1}^{*}\right)
$$

$$
\lambda_{\mathrm{in}_{2 \mathrm{c}}}=\lambda_{\mathrm{in}_{2 \mathrm{n}}}+A_{2}^{*}\left(A_{\mathrm{A}_{2_{\mathrm{c}}}}-A_{\mathrm{A}_{2 \mathrm{n}}}\right)
$$

635 636

$$
\begin{aligned}
& \lambda_{\text {out }_{1}}=A_{\mathrm{A}_{1}}\left(A_{1}^{*}-\frac{\kappa-1}{2} U_{1}^{*}\right) \\
& \lambda_{\mathrm{out}_{2}}=A_{\mathrm{A}_{2 \mathrm{c}}}\left(A_{2}^{*}-\frac{\kappa-1}{2} U_{2}^{*}\right)
\end{aligned}
$$




\section{References}

[1] C. Katsanos, D. Hountalas, T. Zannis, Simulation of a heavy-duty diesel engine with electrical turbocompounding system using operating charts for turbocharger components and power turbine, Energy Conversion and Management 76 (2013) 712-24.

[2] T. Katrašnik, V. Medica, F. Trenc, Analysis of the dynamic response improvement of a turbocharged diesel engine driven alternating current generating set, Energy Conversion and Management 46 (18-19) (2005) $2838-55$.

[3] N. Bayomi, R. El-Maksoud, Two operating modes for turbocharger system, Energy Conversion and Management 58 (2012) 59-65.

[4] J. Fu, J. Liu, B. Deng, R. Feng, J. Yang, F. Zhou, X. Zhao, An approach for exhaust gas energy recovery of internal combustion engine: Steamassisted turbocharging, Energy Conversion and Management 85 (2014) $234-44$.

[5] R. Chacartegui, D. Sánchez, A. Muñoz, T. Sánchez, Real time simulation of medium size gas turbines, Energy Conversion and Management 52 (1) (2011) 713-24.

[6] R. S. Benson, K. H. Scrimshaw, An experimental investigation of nonsteady flow in a radial gas turbine, Proceedings of the Institution of Mechanical Engineers 180 (10) (1965) 74-85.

[7] R. S. Benson, Nonsteady flow in a turbocharger nozzleless radial gas turbine, SAE Technical Paper 740739, 1974. 
[8] A. Dale, N. Watson, Vaneless radial turbocharger turbine performance, in: Proceedings of the IMechE 3rd International Conference on Turbocharging and Turbochargers, paper C110/86, 1986.

[9] A. Dale, N. Watson, A. C. Cole, The development of a turbocharger turbine test facility, in: IMechE Seminar of Experimental Methods in Engine Research and Development, 1988.

[10] M. Capobianco, A. Gambarotta, Unsteady flow performance of turbocharger radial turbines, in: Proceedings of IMechE 4th International Conference on Turbocharging and Turbochargers, paper C405/17, 1990.

[11] D. E. Winterbone, B. Nikpour, G. I. Alexander, Measurement of the performance of a radial inflow turbine in a conditional steady and unsteady flow, in: Proceedings of IMechE 4th International Conference on Turbocharging and Turbochargers, paper C405/015, 1990.

[12] J. H. Yeo, N. C. Baines, Pulsating flow behaviour in a twin-entry vaneless radial-inflow turbine, in: Proceedings of the IMechE 4th International Conference on Turbocharging and Turbochargers, paper C405/004, 1990.

[13] D. E. Winterbone, B. Nikpour, H. Frost, A contribution to the understanding of turbocharger turbine performance in pulsating flow, in: Proceedings of the Institution of Mechanical Engineers internal combustion engine research in universities, polytechnics and colleges conference 1991-1, paper C433/011, 1991. 
[14] J. M. Luján, J. Galindo, J. R. Serrano, Efficiency characterization of centripetal turbines under pulsating flow conditions, in: SAE 2001 World Congress, sAE paper 2001-01-0272, 2001.

[15] N. Karamanis, R. Martinez-Botas, Mixed-flow turbines for automotive turbochargers: steady and unsteady performance, International Journal of Engine Research 3 (3) (2002) 127-38.

[16] S. Szymko, R. F. Martinez-Botas, K. R. Pullen, Experimental evaluation of turbocharger turbine performance under pulsating flow conditions, in: Proceedings of the ASME Turbo Expo 2005: Power for Land, Sea and Air, paper GT2005-68878, 2005.

[17] S. Marelli, M. Capobianco, Steady and pulsating flow efficiency of a waste-gated turbocharger radial flow turbine, Energy 35 (1) (2011) 45965.

[18] A. Costall, R. F. Martinez-Botas, Fundamental characterization of turbocharger turbine unsteady flow behavior, in: Proceedings of the ASME Turbo Expo 2007: Power for Land, Sea and Air, paper GT2007-28317, 2007.

[19] J. H. Yeo, N. C. Baines, Laser velocity measurements in a twin-entry vaneless radial turbocharger turbine, JSME International Journal. Ser. B, Fluids and thermal engineering 37-B (4) (1994) 861-70.

[20] H. Chen, Steady and unsteady performance of vaneless casing radialinflow turbines, Ph.D. thesis, UMIST, University of Manchester, 1990. 
[21] M. Hamel, M. Abidat, S. A. Litim, Investigation of the mixed flow turbine performance under inlet pulsating flow conditions, Comptes Rendus Mécanique 340 (3) (2012) 165-76.

[22] J. Galindo, P. Fajardo, R. Navarro, L. M. García-Cuevas, Characterization of a radial turbocharger turbine in pulsating flow by means of CFD and its application to engine modeling, Applied Energy 103 (2013) $116-27$.

[23] J. Galindo, A. Tiseira, P. Fajardo, L. García-Cuevas, Development and validation of a radial variable geometry turbine model for transient pulsating flow applications, Energy Conversion and Management 85 (2014) 190-203.

[24] M. Nakhjiri, P. F. Pelz, B. Matyschok, L. Däubler, A. Horn, Apparent and real efficiency of turbochargers under influence of heat flow, in: 14th International Symposium on Transport Phenomena and Dynamics of Rotating Machinery, ISROMAC-14, 2012.

[25] N. C. Baines, A. Hajilouy-Benisi, J. H. Yeo, The pulse flow performance and modelling of radial inflow turbines, in: Proceedings of IMechE 5th International Conference on Turbocharging and Turbochargers 1994-06, paper C484/006/94, 1994.

[26] H. Chen, D. E. Winterbone, A method to predict performance of vaneless radial turbines under steady and unsteady flow conditions, in: Proceedings of IMechE 4th International Conference on Turbocharging and Turbochargers, paper C405/008, 1990. 
[27] H. Chen, I. Hakeem, R. F. Martinez-Botas, Modelling of a turbocharger turbine under pulsating inlet conditions, Proceedings of the Institution of Mechanical Engineers, Part A: Journal of Power and Energy 210 (5) (1996) 397-408.

[28] F. Payri, J. Benajes, M. Reyes, Modelling of supercharger turbines in internal-combustion engines, International Journal of Mechanical Sciences 38 (8-9) (1996) 853-69.

[29] J. Macek, J. Vávra, O. Vítek, 1-D model of radial turbocharger turbine calibrated by experiments, in: SAE 2002 World Congress, sAE paper 2002-01-0377, 2002.

[30] A. Costall, S. Szymko, R. F. Martinez-Botas, D. Filsinger, D. Ninkovic, Assessment of unsteady behavior in turbocharger turbines, in: Proceedings of the ASME Turbo Expo 2006: Power for Land, Sea and Air, paper GT2006-90348, 2006.

[31] F. Piscaglia, A. Onorati, S. Marelli, M. Capobianco, Unsteady behavior in turbocharger turbines: experimental analysis and numerical simulation, in: Proceedings of the 8th International Conference on Engines for Automobiles, sAE paper 2007-24-0081, 2007.

[32] J. Macek, O. Vitek, Simulation of pulsating flow unsteady operation of a turbocharger radial turbine, in: SAE 2008 World Congress, sAE paper 2008-01-0295, 2008.

[33] J. R. Serrano, F. J. Arnau, V. Dolz, A. Tiseira, C. Cervelló, A model of turbocharger radial turbines appropriate to be used in zero- and one- 
dimensional gas dynamics codes for internal combustion engine modelling, Energy Conversion and Management 49 (12) (2008) 3729-45.

[34] A. W. Costall, A one-dimensional study of unsteady wave propagation in turbocharger turbines, Ph.D. thesis, Imperial College, University of London, 2007.

[35] M. S. Chiong, S. Rajoo, A. Romagnoli, R. F. Martinez-Botas, Single entry mixed flow turbine performance prediction with 1-D gas dynamic code coupled with mean line model, International Journal of Gas Turbine, Propulsion and Power Systems 4 (2) (2012) 8-16.

[36] M. S. Chiong, S. Rajoo, A. Romagnoli, R. F. Martinez-Botas, Unsteady performance prediction of a single entry mixed flow turbine using 1-D gas dynamic code extended with meanline model, in: Proceedings of the ASME Turbo Expo 2012, paper GT2012-69176, 2012.

[37] M. S. Chiong, S. Rajoo, A. Romagnoli, A. W. Costall, R. F. MartinezBotas, Integration of meanline and one-dimensional methods for prediction of pulsating performance of a turbocharger turbine, Energy Conversion and Management 81 (2014) 270-81.

[38] R. S. Benson, The thermodynamics and gas dynamics of internalcombustion engines, vol. 1, Clarendon Press, Oxford, UK., 1982.

[39] S. Szymko, The development of an eddy current dynamometer for evaluation of steady and pulsating turbocharger turbine performance, Ph.D. thesis, Imperial College, University of London, 2006. 
[40] M. Hajmohammadi, S. Poozesh, M. Rahmani, A. Campo, Heat transfer improvement due to the imposition of non-uniform wall heating for intube laminar forced convection, Applied Thermal Engineering 61 (2) (2013) 268-77.

[41] M. Hajmohammadi, S. Nourazar, A. Campo, S. Poozesh, Optimal discrete distribution of heat flux elements for in-tube laminar forced convection, International Journal of Heat and Fluid Flow 40 (2013) 89-96.

[42] M. Hajmohammadi, M. Rahmani, A. Campo, O. Joneydi-Shariatzadeh, Optimal design of unequal heat flux elements for optimized heat transfer inside a rectangular duct, Energy 68 (2014) 609-16.

[43] J. R. Serrano, P. Olmeda, A. Tiseira, L. M. García-Cuevas, A. Lefebvre, Theoretical and experimental study of mechanical losses in automotive turbochargers, Energy 55 (2013) 888-98.

[44] M. Hajmohammadi, S. Nourazar, On the insertion of a thin gas layer in micro cylindrical Couette flows involving power-law liquids, International Journal of Heat and Mass Transfer 75 (2014) 97-108.

[45] S. Rajoo, Steady and pulsating performance of a variable geometry mixed flow turbocharger turbine, Ph.D. thesis, Imperial College, University of London, 2007.

[46] P. K. Swamee, A. K. Jain, Explicit equations for pipe-flow problems, Journal of the Hydraulics Division 102 (5) (1976) 657-64. 
[47] D. E. Winterbone, R. J. Pearson, The Theory of Engine Manifold Design: Wave Action Methods for IC Engines, Professional Engineering Publishing Limited, 2000.

[48] A. W. Costall, R. M. McDavid, R. F. Martinez-Botas, N. C. Baines, Pulse performance modeling of a twin entry turbocharger turbine under full and unequal admission, Journal of Turbomachinery 133 (2) (2011) 021005-1-9.

[49] N. Mizumachi, D. Yoshiki, T. A. Endoh, A study on performance of radial turbine under unsteady flow conditions, Report of the Institute of Industrial Science 28 (1979) 122-30.

[50] S. M. Futral, C. A. Wasserbauer, Off-design performance prediction with experimental verification for a radial-inflow turbine, TN D-2621, NASA, 1965.

[51] A. J. Glassmann, C. A. Wasserbauer, FORTRAN program for predicting off-design performance of radial inflow turbines, TN D-8063, NASA, 1975.

[52] P. L. Meitner, A. J. Glassmann, Computer code for off design performance analysis of radial inflow turbines with rotor blade sweep, TN TP2199, NASA, 1983.

[53] N. Karamanis, R. F. Martinez-Botas, C. C. Su, Mixed flow turbines: Inlet and exit flow under steady and pulsating conditions, Journal of Turbomachinery 123 (2) (2001) 359-71. 
${ }_{815}$ [54] N. Winkler, H.-E. Ångström, Study of measured and model based generated turbine performance maps within a 1D model of a heavy-duty diesel engine operated during transient conditions, in: SAE 2007 World Congress, sAE paper 2007-01-0491, 2007.

[55] F. Payri, J. Serrano, P. Fajardo, M. Reyes-Belmonte, R. Gozalbo-Belles, A physically based methodology to extrapolate performance maps of radial turbines, Energy Conversion and Management 55 (2012) 149-63. 